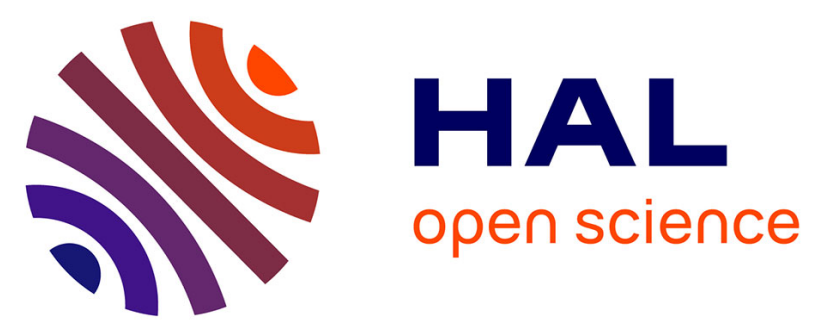

\title{
Territorial scent-marking effects on vigilance behavior, space use, and stress in female Columbian ground squirrels
}

Jeffrey D Roth, F. Stephen Dobson, Peter Neuhaus, Asheber Abebe, Thibaut Barra, Rudy Boonstra, Phoebe D Edwards, Manuel A Gonzalez, Tracey L Hammer, Erwan Harscouet, et al.

\section{To cite this version:}

Jeffrey D Roth, F. Stephen Dobson, Peter Neuhaus, Asheber Abebe, Thibaut Barra, et al.. Territorial scent-marking effects on vigilance behavior, space use, and stress in female Columbian ground squirrels. Hormones and Behavior, 2022, 139, pp.105111. 10.1016/j.yhbeh.2022.105111 . hal-03538717

\section{HAL Id: hal-03538717 https://hal.science/hal-03538717}

Submitted on 21 Jan 2022

HAL is a multi-disciplinary open access archive for the deposit and dissemination of scientific research documents, whether they are published or not. The documents may come from teaching and research institutions in France or abroad, or from public or private research centers.
L'archive ouverte pluridisciplinaire HAL, est destinée au dépôt et à la diffusion de documents scientifiques de niveau recherche, publiés ou non, émanant des établissements d'enseignement et de recherche français ou étrangers, des laboratoires publics ou privés. 
2 Territorial scent-marking effects on vigilance behavior, space use, and stress in female Columbian ground squirrels

4

5
${ }^{1}$ Department of Biological Sciences, Auburn University, Auburn, AL, USA ${ }^{2}$ Université de Strasbourg, CNRS, IPHC UMR 7178, F-67000 Strasbourg, France ${ }^{3}$ University of Strasbourg, Institute of Advanced Sciences (USIAS), 5 allée du Général Rouvillois, 67083 Strasbourg, France

${ }^{4}$ Department of Biological Sciences, University of Calgary, Calgary, AB T2N 1N4, Canada ${ }^{5}$ Department of Mathematics and Statistics, Auburn University, Auburn, AL, USA ${ }^{6}$ Department of Biological Sciences, University of Toronto Scarborough, ON M1C 1A4, Canada

${ }^{7}$ Department of Biological Sciences, University of Veterinary Medicine, Vienna, Austria

*Correspondance vincent.viblanc@iphc.cnrs.fr

\section{Author contributions}

Designed the study: VAV, PN and FSD; collected the data; VAV, JDR, PN, TB, FC, MAG, TLH, EH, MM, CS, MT, PU and FSD; did the laboratory work: PDE, LMC and RB; provided antibodies and expertise on FCM measurement: RP; analyzed the data: VAV, JDR, 
25 AA, CS, and FSD; wrote the manuscript: VAV, JDR and FSD; all authors commented on the manuscript.

\section{Abstract}

28 Social environments can profoundly affect the behavior and stress physiology of group-living animals. In many territorial species, territory owners advertise territorial boundaries to conspecifics by scent marking. Several studies have investigated the information that scent marks convey about donors' characteristics (e.g., dominance, age, sex, reproductive status), but less is known about whether scents affect the behavior and stress of recipients. We experimentally tested the hypothesis that scent marking may be a potent source of social stress in territorial species. We tested this hypothesis for Columbian ground squirrels (Urocitellus columbianus) during lactation, when territorial females defend individual nestburrows against conspecifics. We exposed resident lactating females, on their territory, to the scent of other lactating females. Scents were either from unfamiliar females, kin relatives (a mother, daughter, or sister), or their own scent (control condition). We expected resident females to react strongly to novel scents from other females on their territory, displaying increased vigilance, and higher cortisol levels, indicative of behavioral and physiological stress. We further expected females to be more sensitive to unfamiliar female scents than to kin scents, given the matrilineal social structure of this species and known benefits of cobreeding in female kin groups. Females were highly sensitive to intruder (both unfamiliar and kin) scents, but not to their own scent. Surprisingly, females reacted more strongly to the scent of close kin than to the scent of unfamiliar females. Vigilance behavior increased sharply in the presence of scents; this increase was more marked for kin than unfamiliar

47 female scents, and was mirrored by a marked $131 \%$ increase in free plasma cortisol levels in the presence of kin (but not unfamiliar female) scents. Among kin scents, lactating females were more vigilant to the scent of sisters of equal age, but showed a marked $318 \%$ increase in 
50 plasma free cortisol levels only in response to the scent of older and more dominant mothers.

51 These results suggest that scent marks convey detailed information on the identity of 52 intruders, directly affecting the stress axis of territory holders.

53

54 Keywords: glucocorticoids, HPA axis, kin selection, olfaction, resource holding 55 potential, territoriality

56

57

58 
60 Many species use scent as a form of chemosensory communication in a variety of social contexts (Ralls 1971; Johnson 1973; Bel et al. 1999). Scent-marking occurs via the deposition of secretions from exocrine scent glands or via odorous marks deposited in urine and feces, on strategic substrate locations. Both time and energy investments are needed to produce olfactory secretions and maintain volatile compounds active in the environment (Radwan et al. 2006). However, this form of social communication allows territory owners, in their absence, to advertise their quality to tentative mates (Johansson and Jones 2007; Boulet et al. 2010), and/or resource holding potential to tentative competitors, while minimizing active resource-defense. This circumvents escalation of risky contests over resources, such as territories or mates (Hurst and Rich 1999; Gosling and Roberts 2001; Stockley et al. 2013).

As scent-marking is thought to convey honest information on the identity, condition, and social status of the bearer, numerous studies have focused on unraveling the attributes signaled by odorous secretions. Scents reflect information on individual sex and age (Kean et al. 2011; Vaglio et al. 2016), familiarity (Hare 1994), genetic similarity and kinship (Mateo 2003; Leclaire et al. 2013), genetic dissimilarity or compatibility (Wedekind et al. 1995; Charpentier et al. 2008), reproductive status (Harris and Murie 1984; Scordato and Drea 2007), health and immune status (Zala et al. 2004; López and Martín 2005), hormonal status and stress levels (Lumley et al. 1999; Yamaguchi et al. 2005; Shimozuru et al. 2006), and social rank (Scordato and Drea 2007; Vaglio et al. 2016). The complexity of odor signals has also been found to increase with social complexity (e.g. in Eulemur species; delBarco-Trillo et al. 2012), indicating the importance of scent communication in social species.

Despite this wealth of studies on the physiological/individual determinants of scentmarking, fewer studies have considered the effects that scent-marks have on the behavior and physiology of recipients. Those that have done so have mostly focused on inter-specific 
84 relationships, e.g., the effect of predator scents on prey stress responses via modulation of the hypothalamo-pituitary-adrenal (HPA) axis function and secretion of glucocorticoid (stress) hormones by the adrenal glands (Apfelbach et al. 2005; Fletcher and Boonstra 2006; Monclús et al. 2006; but see Zuri et al. 1998). However, if scent-marking is used to effectively advertise social dominance or ownership of resources, one might expect scent-marks to have potent effects on the receiver's behavior and stress physiology in social contexts (Roberts 1998; Zuri et al. 1998). This should especially be the case in species where social systems are characterized by shifting spatio-temporal territories that require both active defense and regular up-keep of ownership advertisement by scent-marks. For instance, many sciurids rely on scents to mark the boundaries of territories defended during critical time periods of the annual cycle of mating, gestation, lactation, and weaning of offspring (Steiner 1974; Ouellet and Ferron 1988; Ferron and Ouellet 1989; Brady and Armitage 1999). The boundaries of those territories are likely to shift both within and over seasons, depending on the age, dominance rank, and reproductive status of the territory holder.

We tested the hypothesis that scent marking constitutes a source of social stress in territorial species, using Columbian ground squirrels (Urocitellus columbianus) as a model system. Columbian ground squirrels are sciurid rodents characterized by a matrilineal social system where related females share adjacent and overlapping territories over generations

102 (King and Murie 1985; King 1989; Arnaud et al. 2012) and males are the dispersing sex 103 (Wiggett and Boag 1989; Neuhaus 2006). Resident males show strong patterns of 104 territoriality during the mating season (Murie and Harris 1978), allowing preferential access 105 to females that share their territory (Manno and Dobson 2008). After reproduction, male territoriality subsides and females become more territorial during the subsequent gestation 107 and lactation periods (Festa-Bianchet and Boag 1982; Murie and Harris 1988). Both males 108 and females display scent-marking behavior, particularly during mating, gestation, and 
109 lactation (Steiner 1974; Betts 1976). Scents are deposited by rubbing apocrine glands located

110 at the oral angles of the mouth (Kivett et al. 1976; Kivett 1978), the anogenital area and a

111 dorsal-glandular area of the body (Steiner 1974) against the substrate. There is clear evidence

112 that scent is an important means of social communication in this species, either related to

113 mating behavior (determination of female reproductive status from vaginal scent marks;

114 Harris and Murie 1984); fear (anal gland pulsating during hostile encounters; Steiner 1970;

115 Steiner 1974); or the discrimination of familiar and unfamiliar conspecifics (oral scents;

116 Harris and Murie 1982; Hare 1994). In an experimental study of Columbian ground squirrels,

117 Raynaud \& Dobson (2011) found that females were more attentive to the scent of other

118 females than males: Presented with conspecific scents, females invested more time re-

119 marking female than male scent marks. These authors hypothesized that this behavior

120 reflected female territory advertisement and protection of the litter, which may be especially

121 important during lactation. During this period, infanticide by other, mostly unrelated,

122 lactating females is known to occur (Balfour 1983; Dobson 1990; Hare 1991; Stevens 1998).

123 Here, we exposed lactating focal females on their territories to the scents of other

124 lactating females, and tested the consequences of this exposure on the behavior and stress

125 physiology of territory owners. We collected lactating female scents on acrylic cubes (by

126 rubbing the cubes on the angulo-oral glands) (see Harris and Murie 1982; Raynaud and

127 Dobson 2011). The scented cubes were then placed around the nest burrow of a focal female,

128 testing her behavioral and physiological (HPA) response to the scent of either $(i)$ an

129 unfamiliar female, (ii) a kin female, or (iii) herself. If scent marking indeed constitutes a 130 source of social stress, we expected to observe marked behavioral and HPA responses of

131 females to the presence of novel scents on their territory. After exposure to conspecific

132 scents, compared to her own scent or no scent conditions, we expected focal females to 133 devote an increased proportion of time to vigilance behavior, and to show heightened HPA 
134 activity measured through increased levels of blood cortisol and fecal cortisol metabolites

135 (Bosson et al. 2009). We also expected females to display increasing amounts of scent

136 marking behavior on their territory, to interact more with scented cubes, and to spend more

137 time exploring their territorial boundaries seeking out the intruder. Because female

138 Columbian ground squirrels are more tolerant of close female kin (King \& Murie 1985; King

139 1989; Viblanc et al. 2016), we expected the effects of scent marks to be stronger for 140 unfamiliar than for kin scents. However, because mothers appear to be dominant over 141 daughters in this species (Harris \& Murie 1984; Wigget \& Boag 1992; Viblanc et al. 2016;

142 Sosa et al. 2020), we also expected females' behavioral and physiological stress responses to 143 be stronger when exposed to the scent of their mother than to the scent of a daughter or 144 littermate sister. Differences in terms both of behavioral and physiological reactions to 145 different scent marks would indicate that subtle social information on identity was conveyed 146 by chemical signals.

148 MATERIAL AND METHODS

\section{Data collection and study site}

150 The study was conducted during the 2017 and 2018 breeding seasons. We studied lactating 151 females in three neighboring colonies of Columbian ground squirrels (Meadow B, Meadow C 152 and DOT) that were actively monitored as part of long-term studies on the behavior and 153 ecology of those animals. The colonies are located in the Sheep River Provincial Park, 154 Alberta, Canada (Meadow B: 50³8' 10.73" N; 114 39' 56.52" W; 1524 m; 2.0 ha; Meadow 155 C: $50^{\circ} 37^{\prime} 44.2^{\prime \prime} \mathrm{N} ; 114^{\circ} 41^{\prime} 18.4^{\prime \prime} \mathrm{W} ; 1555 \mathrm{~m}$; 1.5 ha; and DOT: $50^{\circ} 38^{\prime} 59.74^{\prime \prime} \mathrm{N} ; 114^{\circ} 39^{\prime}$ $15641.79 " \mathrm{~W} ; 1545 \mathrm{~m} ; 3.0 \mathrm{ha})$. In each year, females were followed throughout reproduction 157 from emergence from hibernation in early April to the weaning of offspring in early to mid158 July (Neuhaus 2000; Dobson et al. 2020). Female mating dates were determined from visual 
159 observations of above ground consortships with males and inspection of genitalia upon 160 trapping (presence of a copulatory plug or sperm in vaginal smears or fur; Murie 1995; Raveh

161 et al. 2010). Gestation lasts 24 days, upon which females give birth to an average of three

162 (one to seven) altricial offspring in a specially constructed nest burrow (Dobson \& Murie 163 1987; Murie 1995). Lactation lasts 27 days, after which, weaned offspring first emerge 164 above ground (Murie \& Harris 1982; Dobson et al. 1992).

165

\section{Scent collection}

167 We collected female ground squirrel scents following the protocol developed through 168 previous investigations on Columbian ground squirrels (Harris \& Murie 1982; Raynaud \& 169 Dobson 2011). We used $3.7 \mathrm{~cm}^{3}$ acrylic cubes to collect oral gland scents by rubbing the 170 cubes ( 3 times per side) on the oral angles of ground squirrels that were either female kin 171 (littermate sister, daughter, or mother), an unfamiliar female (from other monitored 172 populations), or the focal female being tested. We focused on collecting only female scents in 173 this study, since previous results had indicated that females are more attentive to the scent of 174 other females than males during gestation and lactation (Raynaud \& Dobson 2011). We 175 ensured that each face of the cube was properly marked, confirmed by the presence of an oily 176 streak mark and characteristic smell. Scent cubes were prepared in the afternoon preceding 177 the experimental trial (see below) and kept in an airtight Ziploc® bag at $4^{\circ} \mathrm{C}$ overnight until 178 use. After each trial, the cubes were washed with soap and water, rinsed with boiling water, 179 and rinsed a final time with $90 \%$ ethanol, before being air dried and stored in an airtight 180 Ziploc® bag until further scent collection. 
183 Nest burrows were identified during gestation by field observations of females stocking them with dry grass material from the meadow (McLean 1978). The experimental trial proceeded in 3 phases: were deployed around a focal female's nest burrow in an equilateral triangle at a $30-\mathrm{cm}$

188 distance from the nest entrance. Cubes were deployed on small metal pins at $\sim 5$-cm height off the ground and left for a period of 4 days to allow the female to habituate to the presence of these novel objects.

Phase 2 'Control = unscented cubes': On day 4, an observer arrived at the colony early in the day ( 6:00 am) before the female had emerged from her nest burrow. Cubes were replaced with fresh unscented cubes and the observer took position on a 3-m tall observation bench, which were generally located some 10 to $30 \mathrm{~m}$ from the nest burrows of interest. Replacing the cubes by fresh unscented cubes insured that we captured the behavior of individual females before they were exposed to a given scent, each female thus serving as her own control during the experiment. Upon morning emergence of the female from her nest burrow, the observer scored her behavior and location for a period of 30 minutes (see below). The observer was unaware of the type of scent provided, so that observations were blind. Depending on the year, either the female was captured $\sim 7$ hours following her emergence from the nest burrow and a fecal sample collected (in 2017, see below), or the female was captured immediately following the 30-min observation period and a blood sample collected usually within 3 minutes of capture (in 2018, see below). of an unfamiliar female, or the focal female's own scent (control). 
212 females were tested repeatedly in different years, and so we controlled for female identity in

213 statistical analyses (see below). On average, the age distribution of females was fairly balanced between groups (female age in kin scent group: mean $( \pm \mathrm{SD})=4.1 \pm 1.9$ y.o., range $=2-9$ y.o; female age in unfamiliar scent group: mean $=4.3 \pm 2.0$ y.o, range $=2-9$ y.o; female age in own scent group: mean $=4.1 \pm 1.8$, range $=1-8)$. Within the kin group,

217 females exposed to the scent of a daughter were slightly older (mean $=6.3 \pm 1.3$ y.o., range $=$ $2184-9$ y.o.) than those exposed to the scent of a mother (mean $=3.0 \pm 0.9$ y.o., range $=2-5$ y.o.) or a sister (mean $\pm \mathrm{SD}=3.7 \pm 1.6$ y.o., range $=2-7$ y.o.). We thus controlled for female age as a covariate in subsequent analyses to account for potential age effects on behavioral and physiological variables.

\section{Behavioral observations}

224 Behavioral observations were carried out during lactation, from the $18^{\text {th }}$ of May to the $8^{\text {th }}$ of 225 June in 2017, and from the from the $23^{\text {rd }}$ of May to the $7^{\text {th }}$ of June in 2018. Each female was 226 observed by the same observer during the entire experimental trial (phases 2, and 3). This 227 required 1-7 observers daily in 2017 and 1-8 observers in 2018. We used fixed-interval point 228 sampling of behaviors (Martin \& Bateson 2021). Females were observed every minute, for 229 30-min periods. Only the behavior on the minute mark was checked on a pre-defined behavioral spread sheet. Each minute, the observer also recorded the exact position of the animal on a cartesian $10 \times 10 \mathrm{~m}$ grid, delimited by colored flags placed throughout the study site. Thus, the position of the animal could be estimated to within about a 1-m resolution 
233 during the observation period. Scored behaviors included: vigilance, locomotion, foraging, 234 grooming, resting, alarm calling, aggressive (chases and fights) and amicable (sniffing)

235 interactions. Vigilance behavior was scored whenever the animal was sitting still on its hind 236 legs or on all four paws, its head pointing away from the ground, scanning the environment. 237 If an animal was temporarily out of sight (e.g., behind a tree or rise in the ground, in a 238 burrow, etc.), an "out of sight" category was scored. In cases where the animal was lost for an extended period of time, observations were discarded. In addition to the above behaviors scored on the minute mark, we recorded and summed all occurrences of (1) cube interactions

241 (licking, biting, scratching or sniffing a cube) and (2) scent marking (scratching and/or 242 rubbing the ground with the cheek or the lateral side of the body, rubbing the cubes with the 243 cheek) during the 30-minute observation period. Because cube interactions were very rare 244 (Appendix 1), we pooled our observations into a binomial variable (interaction vs. no interaction with cubes) for further analyses (see below).

\section{Feces and blood sampling}

In 2017, we collected fecal samples to measure fecal cortisol metabolites (FCMs) as an integrative measure of female stress. Females were captured approximately 7 hours following control observations (phase 2) or first exposure to the scent (phase 3),

251 corresponding to the time required for glucocorticoid plasma changes to be reflected in FCM 252 changes (Bosson et al. 2009). Fecal samples were collected into 2-mL sterile vials as females 253 defecated during handling, or from the floor of the trap. In the latter case, the female was 254 always observed defecating in the trap and the feces collected immediately. The traps were systematically cleaned before being deployed to ensure fecal samples corresponded to 
were immediately stored on ice packs in the field and transferred to a $-20^{\circ} \mathrm{C}$ freezer within 30 min of collection.

In 2018, we collected blood samples to measure female's blood cortisol levels

260 immediately after the 30 min of control (phase 2) and exposure to a scent (phase 3 ). A few 261 females $(\mathrm{N}=12)$ were also bled in 2017 , in which case they were not sampled for feces, so as 262 to not bias results with stress from the capture. Following the 30-min observation period, 263 females were trapped and a $0.5 \mathrm{~mL}$ blood sample was collected from the saphenous vein 264 using a $27-\mathrm{G}$ needle fitted to a $1 \mathrm{~mL}$ heparinized syringe. An observer would set a trap on the 265 female's territory, and keep watch until the targeted female entered the trap, in general within 266 minutes of deployment and within 30 minutes maximum. As soon as the trap-door shut, a 267 stop watch was started and the time until the animal bled was completed was timed. We 268 aimed to sample blood within 3-min of trapping (mean $\pm \mathrm{SD}=2.75 \pm 0.97$ minutes, $\min =$ $2691.40, \max =7.00)$ to capture baseline CORT levels. Although 20 samples out of 93 were 270 acquired after 3 min (on average at $4.44 \pm 1.12$ minutes, $\min =3.05$, $\max =7.00$ ), we decided 271 to keep those in our analyses, as total (Pearson's $r=0.11, P=0.33)$ and free $(r=0.03, P=$ 272 0.80) cortisol levels were not significantly correlated to sampling time in our data (Appendix 273 2). Syringes were kept on ice packs in a cooler box in the field. Blood was centrifuged $274(3,000 \mathrm{~g}$ for $10 \mathrm{~min})$ within $30 \mathrm{~min}$ of collection, plasma and blood cells were separated and 275 frozen at $-20^{\circ} \mathrm{C}$ until the end of the field season. Both fecal and blood samples were shipped at the end of the season on dry ice to the 277 University of Toronto Scarborough (Canada), and were kept frozen at $-80^{\circ} \mathrm{C}$ until analyses.

\section{Stress hormone analyses}

280 Fecal cortisol metabolites (FCMs) 
281 FCMs represent the fraction of metabolized GCs that are excreted in the feces and reflect 282 biologically active free levels of plasma GCs (Bosson et al. 2009; Sheriff et al. 2010; Fauteux 283 et al. 2017). Lyophilized fecal samples were frozen in liquid nitrogen, and pulverized with a 284 small grinding pestle. We extracted FCMs from $0.054 \pm$ (s.d.) $0.003 \mathrm{~g}$ of pulverized-sample 285 by vortexing it (30 min at $1450 \mathrm{rpm})$ in $1 \mathrm{~mL}$ of $80 \%$ methanol (v/v). FCMs (ng/g dried

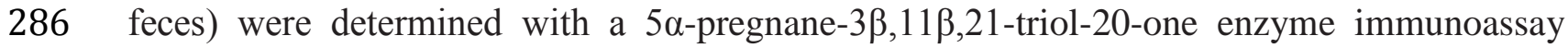
287 (EIA), designed to measure metabolites with a $5 \alpha-3 \beta, 11 \beta$-diol structure (see Touma et al. 2003 for cross-reactivities of the antibody), which has been previously validated for use in Columbian ground squirrels (Bosson et al. 2009). We ran all samples in duplicate. Sample pools of low ( 70\% binding) and high ( $~ 30 \%$ binding) values were used as controls and run on all plates. Intra-assay coefficients of variation based on the pools were $17.38 \%$ (low pool) and $8.03 \%$ (high pool), and the mean inter-assay coefficient of variation based on the pools was $13.93 \%$ (low pool) and $3.94 \%$ (high pool). All sample duplicates had a coefficient of 294 variation of $15 \%$ or less.

\section{Plasma total cortisol}

297 We measured plasma total cortisol levels by radioimmunoassay (RIA) using a commercially 298 available kit (ImmuChem ${ }^{\mathrm{TM}}$ Coated Tube Cortisol ${ }^{125}$ I RIA Kit; MP Biomedicals, LLC, 299 Orangeburg, NY, USA). The antibody has a cross-reactivity of 5.5\% to corticosterone and 300 less than $3 \%$ to other naturally occurring steroids. Preliminary validation to ensure 301 parallelism was done using different cortisol concentrations in CGS plasma (Bosson \& 302 Boonstra; unpublished data). We used the following modifications compared to the kit 303 protocol. Each plasma sample was analyzed in duplicate with $10 \mu$ of plasma being added 304 per RIA tube along with $1 \mathrm{~mL}$ of Cortisol- ${ }^{125} \mathrm{I}, 20 \mu \mathrm{NH} \mathrm{NH}_{4} \mathrm{OH}$ (to saponify triglycerides), and $30540 \mu 1$ double-distilled $\mathrm{H}_{2} \mathrm{O}$ prior to incubation. Samples were run against a 6-point standard 
306 curve $(0-100 \mathrm{ng} / \mathrm{mL})$ on an automatic gamma counter (Wizard ${ }^{2} 2470$, PerkinElmer, Waltham, 307 MA, USA). This method has a mean recovery of $102.4 \pm 2.54 \%(\mathrm{~N}=10$, range $91-117 \%)$ and 308 a detection limit of $17 \mathrm{pg} / 10 \mu \mathrm{l}$. The mean intra-assay coefficient of variation was $12.55 \%$ 309 (low pool) and $11.40 \%$ (high pool), and the mean inter-assay coefficient of variation was $3107.20 \%$ (low pool), and 9.72\% (high pool). All duplicate samples had a coefficient of variation 311 of $8 \%$ or less.

We determined how much plasma cortisol was free and not bound to its main carrier 313 protein, corticosteroid-binding globulin (CBG). For this, we measured CBG for each sample 314 as the maximum corticosteroid-binding capacity (MCBC) with the saturated ligand method 315 described in McDonald et al. (1981) and then calculated the free cortisol. We followed the 316 MCBC protocol outlined in Delehanty and Boonstra (2009) with slight modifications. 317 Cortisol (Sigma Aldrich, St. Louis, MO, USA) was diluted to $20 \mathrm{ng} / 10 \mu \mathrm{EtOH}$, and $10 \mu \mathrm{l}$ 318 was added to 12 × $75 \mathrm{~mm}$ polypropylene tubes and dried under filtered air. Once dry, 319 duplicate $10 \mu \mathrm{l}$ of plasma were added to the tubes, followed by $100 \mu \mathrm{l}$ of cortisol [1,2,6,7-

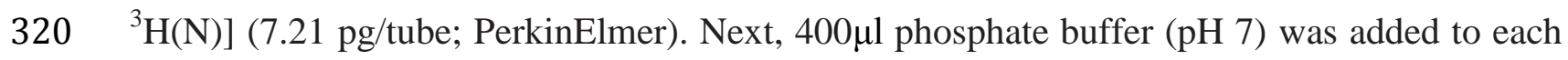
321 tube and allowed to equilibrate at room temperature for 30 minutes, and left overnight at $4{ }^{\circ} \mathrm{C}$. 322 The following morning, $200 \mu \mathrm{l}$ of dextran-coated charcoal was added to separate bound and 323 free hormone. After a 10 -minute incubation at $4^{\circ} \mathrm{C}$, the samples were centrifuged at $2800 \mathrm{rpm}$ 324 for 10 minutes, and $500 \mu \mathrm{l}$ of supernatant was added to $3.5 \mathrm{~mL}$ of scintillation fluid (Gold 325 Star, Meridian Biotechnologies Ltd., Surrey, ENG, UK), vortexed, and left to equilibrate in 326 the dark for at least 4 hours before being read in a scintillation counter (Tri-Carb 3110 TR, 327 PerkinElmer). The intra- and inter-assay coefficients of variation based on the pools were $3287.57 \%$ and $9.67 \%$, respectively. All duplicate samples had a coefficient of variation of $11 \%$ 329 or less. 
331 MCBC values, a value for albumin, and the CBG equilibrium dissociation constant $\left(\mathrm{K}_{\mathrm{d}}\right)$. We 332 assumed the albumin concentration and proportion of cortisol bound to albumin were 333 comparable to the values calculated for Arctic ground squirrels $(2.54 \mathrm{~g}$ albumin/100 $\mathrm{mL}$ 334 plasma; proportion bound $=0.19)$ in Boonstra and McColl $(2000)$, and we used a $\mathrm{K}_{\mathrm{d}}$ value of $3355.1 \mathrm{nM}$ calculated in Delahanty et al. (2015).

\section{Statistical analyses}

338 All statistical analyses were performed using R v. 4.0.2 (R Core Team 2020). To understand 339 how exposure to scents might have influenced female stress, we focused on behaviors 340 relevant to territoriality including: (1) the time devoted to vigilance vs. foraging or vs. other 341 behaviors, (2) the amount of territorial marking performed (3) the occurrence of interactions 342 with scented cubes, and (4) exploration behavior; and on two aspects relevant to the HPA 343 axis functioning: (5) FCM levels, and (6) plasma cortisol levels.

\section{Vigilance behavior}

346 Female vigilance behavior in response to the scents was analyzed using multinomial logistic 347 regression (MLR; package 'mlogit' in R), accounting for repeated measures on females in 348 separate years. The multinomial response outcomes (dependent variable) included 349 'vigilance', 'foraging', and 'other' behaviors ( $<7.5 \%$ of total observations). We ran separate 350 regressions for each scent category (unfamiliar, kin or own scents - and within the kin category: for mother, daughter, or sister scents) and specified treatment (unscented vs. scented cubes) as the independent variable. Thus, we tested how female vigilance behavior

353 changed in proportion relative to foraging or other behaviors when females were exposed to a

354 scent compared to the no scent situation (no scent fixed as reference level). Results are given 
as odds ratios along with $95 \%$ confidence intervals. Significant odds ratios have confidence intervals not overlapping 1 and can be interpreted as the odds of increasing $(>1)$ or decreasing $(<1)$ vigilance relative to foraging or other behaviors for a transition from no-scent to scent condition.

\section{Territorial marking and interactions with cubes}

361 The number of occurrences recorded for territorial scent markings and cube interactions during the 30-min observations was heavily zero-inflated (Appendix 1). Thus, we first analyzed the likelihood to engage in scent marking or to interact with cubes as a binomial

364 response (0/1). For this, we ran separate generalized linear mixed effects models (GLMM;

365 binomial error structure, 'Ime4' package in R) for unfamiliar, kin or own scents categories 366 (and within the kin category: for mother, daughter, or sister scents) with the likelihood to engage (1) or not (0) in a scent marking or cube interactions specified as the dependent variable, and treatment (no-scent vs. scented cubes) as the independent variable. We originally included year and female ID as random effects in the models to account for year effects and repeated observations on individuals, but removed them if models did not converge and their associated variance could not be estimated.

373 Appendix 1), we focused on the number of scent marks actually performed for individuals 374 that scent-marked (i.e., all data > 0). For this, we ran separate GLMMs (Poisson error 375 distribution), with the number of scent marks as the dependent, and treatment (no-scent vs. scented cubes) as the independent variable for each of our scent treatments (unfamiliar, kin or own scents). Here also, we included year and female ID as random effects in the models, but removed them if models did not converge and their associated variance could not be estimated. When working at the kin level (mother, daughter, or sister scents), because of low 
sample size $\mathrm{N}<5$ in some of the categories, we tested the difference between control (noscent cubes) and treated (scented cubes) using exact permutation tests ('lmp' function from the 'ImPerm' package in R; Wheeler \& Torchiano 2016).

\section{Exploration behavior}

385 To evaluate the effects of scent marks on female exploration behavior, we quantified: (1) the overall size of the area (in $\mathrm{m}^{2}$ ) used over the 30-min observation period, and (2) how far a female ventured from her nest burrow within the 30-min. First, we calculated the area used during the observations using Minimum Convex Polygons (MCP, 'adehabitatHR' package in R). Since our objective was to evaluate the maximal area covered by females over the 30-min observation period, we considered all observation coordinates (MCP 100\%) corresponding to spatial coordinates recorded by the observers on the minute mark. We then ran separate linear mixed models (LMM) for own, kin and unfamiliar scent categories (and within kin for mother, sister or daughter scent categories) to test for the effects of treatment (no-scent vs. scented cubes) on area use (dependent variable). We included year and female ID as random effects in the models, but removed them if models did not converge and their associated variance could not be estimated.

Second, we calculated the distance a female ventured from her nest burrow (her starting location) at each minute of the 30 -min observation period. We then ran separate Generalized Additive Mixed Models (GAMM, 'mgcv' and 'gaam4' packages in R) for own, 400 kin and unfamiliar female scent categories (and within kin for mother, sister or daughter scent categories) to determine how this distance varied with time in control (no-scent cubes) and treatment (scented cubes) conditions. Differences between conditions were assessed using 403 overlaps in $95 \%$ confidence intervals of the GAMMs. The estimated degree of freedom (edf) 404 of GAMMs' smoothing function are reported. 
Physiological stress

Female fecal cortisol metabolites (FCM; obtained in 2017; 7 hours after the exposure to unscented or scented cubes) and plasma cortisol levels (CORT; obtained in 2017 and 2018; 409 immediately after the exposure to cubes) were analyzed using separate LMMs. FCM and 410 CORT levels (either total CORT, free CORT or MCBC) were specified as dependent 411 variables in the separate models for own, kin and unfamiliar scent categories and the 412 treatment (no-scent vs. scented cubes) specified as an independent variable. Here also, female 413 ID (and year for the plasma CORT data) were entered as random variables for LMMs, but 414 removed if their associated variance could not be estimated. Again, when working at the kin 415 level, because of low sample size of $\mathrm{N}<5$ in some of the categories, we tested the difference between control (no-scent cubes) and treated (scented cubes) using exact permutation tests

417 ('Imp' function from the 'ImPerm' package in R; Wheeler \& Torchiano 2016).

\section{Ethics}

420 This study was approved by the Auburn University Institutional Animal Care and Use 421 Committee, with additional approval by the University of Calgary. Permits for conducting research and collecting samples in the Sheep River Provincial Park were obtained from 423 Alberta Environment and Parks (research permits $\mathrm{n}^{\circ} 58954, \mathrm{n}^{\circ} 58955$ ) and Alberta Tourism, 424 Parks, and Recreation (research and collection permit $\mathrm{n}^{\circ} 17-046$ and $\mathrm{n}^{\circ} 18-448$ )

\section{RESULTS}

\section{Vigilance behavior}

428 Controlling for age and compared to the no-scent condition, females exposed to either 429 unfamiliar or kin scents, but not those exposed to their own scent, engaged in significantly 
430 more vigilance than foraging or other behaviors over the 30-minute period (Fig 1A). For

431 females exposed to unfamiliar scents, the odds of engaging into vigilance rather than foraging

432 or other behaviors increased by 1.40 and 1.59 , respectively, compared to no-scent conditions

433 (multinomial; $z=2.98$ and $3.77, P=0.003$ and $P<0.000$ ). For females exposed to kin scents,

434 these odds increased by 1.82 and $1.91(z=4.63$ and 4.54 , both $P<0.000)$ compared to no-

435 scent conditions, whereas the odds did not change significantly (odds ratios $=1.24$ and 1.00;

$436 z=1.60$ and $0.02, P=0.11$ and 0.99$)$ for females exposed to their own scents vs. no-scent

437 conditions.

438 Controlling for age, significant increases in vigilance compared to foraging or other

439 behaviors were evident among females exposed to scents of female kin (Fig 1B). For females

440 exposed to the scent of a sister, the odds of engaging in vigilance rather than foraging or other

441 behaviors increased by 1.86 and 2.99, respectively, compared to no-scent conditions ( $\mathrm{z}=3.12$

442 and 5.04, $\mathrm{P}=0.002$ and $\mathrm{P}<0.000)$. For females exposed to the scent of a daughter, these

443 odds increased by 2.29 and 1.50 , respectively, compared to no-scent conditions $(\mathrm{z}=3.09$ and

$4441.35, \mathrm{P}=0.002$ and 0.18 ). Finally, for females exposed to the scent of their mother these odds

445 increased by 1.62 and 1.21 , respectively, compared to no-scent conditions $(\mathrm{z}=2.08$ and 0.76 ,

$446 \mathrm{P}=0.04$ and 0.45$)$.

447

448 Territorial scent-marking and interactions with cubes

449 Territorial scent-marking

450 We observed territorial scent-marking by resident females in $42 \%$ of our observation periods.

451 Controlling for age, the probability for females to scent-mark (GLMM; binomial 1/0) during

452 the 30-min observation period did not differ between scent (treatment) and no-scent (control)

453 conditions, regardless of the scent considered (own scent: $27 \%$ vs. $34 \%$ for marking

454 probability in the scent vs. no-scent condition, respectively; odds ratio $=0.72, \mathrm{CI}_{95}=[0.23$, 
455

456

457

458

459

460

461

462

463

464

465

466

467

468

469

470

471

472

473

474

475

476

477

478

479

2.24], $z=-0.57, P=0.57$; kin scent: $57 \%$ vs. $38 \%$, odds ratio $=2.16, \mathrm{CI}_{95}=[0.69,6.82], z=$ 1.32, $P=0.19$; unfamiliar scent: $44 \%$ vs. $40 \%$, odds ratio $=1.18, \mathrm{CI}_{95}=[0.38,3.68], z=$ 0.29, $P=0.77$ ) (Fig 2A). Controlling for age, when considering the kin group only, females exposed to the scent of a sister had a higher probability of scent-marking in the presence than in the absence of scent (53\% vs. $13 \%$; odds ratio $=7.95, \mathrm{CI}_{95}=[1.45,66.28], z=2.20, P=$ 0.03). This was not the case, however, for females exposed to the scent of their mother $(70 \%$ vs. $81 \%$; odds ratio $\left.=0.52, \mathrm{CI}_{95}=[0.05,5.24], z=-0.55, P=0.58\right)$. For females exposed to the scent of a daughter, age was removed from the analysis since the model would not converge. Females exposed to the scent of a daughter had a similar probability of scentmarking when exposed to a scent or not $\left(50 \%\right.$ vs. $50 \%$; odds ratio $=1.00, \mathrm{CI}_{95}=[0.09$, 11.30], $z=0.00, P=1.00)($ Fig 2B).

For females that did engage in scent-marking, controlling for age, the number of scent-marks performed was $48 \%$ lower in the treated condition (scent present) for the kin group (GLMM; Poisson, count data; estimate $=-0.48 ; \mathrm{CI}_{95}=[-0.83,-0.14], z=-2.72, P=$ 0.007), but did not differ significantly between unscented and scented conditions for other groups (own scent: estimate $=-0.13, \mathrm{CI}_{95}=[-0.74,0.42], z=-0.45, P=0.65$; unfamiliar scent: estimate $\left.=0.24, \mathrm{CI}_{95}=[-0.07,0.56], z=1.53, P=0.13\right)($ Fig 3A). However, this appeared to be the result of one female that spent a substantial amount of time scent marking. When this female was removed from the analysis, the effect was still negative (i.e., females exposed to a kin scent decreased territorial marking by $25 \%$, on average, in the presence of the scent) but no longer significant (estimate $=-0.23, \mathrm{CI}_{95}=[-0.65,0.18] ; z=-1.10, P=$ 0.27). Within the kin group (Fig 3B), we found no significant difference in the number of scent marks performed regardless of whether females were exposed to the scent of a daughter (Exact permutation tests; $\mathrm{P}=0.27)$, a sister $(\mathrm{P}=0.45)$, or a mother $(\mathrm{P}=0.69)$. 
480

481

482

483

484

485

486

487

488

489

490

491

492

493

494

495

496

497

498

499

500

501

502

503

504

\section{Interactions with cubes}

Resident females were observed interacting with cubes in $11 \%$ of our observation periods. Controlling for age, females exposed to unfamiliar scents interacted significantly more with cubes in the scent vs. no-scent condition $\left(16 \%\right.$ vs. $0.01 \%$; odds ratio $=22.01, \mathrm{CI}_{95}=[1.67$, 290.73], $z=2.35, P=0.02$ ) (Fig 4). Females also interacted significantly more with cubes when a kin scent was present vs. no-scent, though the predicted probabilities of interaction were, overall, extremely low $\left(0.0005 \%\right.$ vs. $0.000003 \%$; odds ratio $=184.32, \mathrm{CI}_{95}=[1.38$, 24699.21], $z=2.09, P=0.04)$. In contrast, females did not interact significantly more with cubes in the 'own' condition, regardless of whether a scent was present or not (3\% vs. 7\%; odds ratio $\left.=2.08, \mathrm{CI}_{95}=[0.19,46.23], z=0.58, P=0.56\right)$. The low number of cube interactions precluded us from meaningful analyses of the data within the kin category.

\section{Exploration behavior}

Space use

Controlling for age, no significant difference was found in the areas covered by females during the 30-min observation period between the no-scent and scent conditions for females exposed to unfamiliar scents $\left(\mathrm{LMM}\right.$; estimate $=-17.85 ; \mathrm{CI}_{95}=[-134.00,98.30], t=-0.30, P=$ 0.76), to kin scents (estimate $=59.46 ; \mathrm{CI}_{95}=[-39.45,158.37], t=1.18, P=0.24$ ), or to their own scent (estimate $=-75.06 ; \mathrm{CI}_{95}=[-170.10,19.98], t=-1.55, P=0.12$ ) (Fig 5a). On average, the area covered by females was similar for all 3 groups (unfamiliar female scent: area $=260.32 \pm 30.34 \mathrm{~m}^{2}$; kin scent: $240.68 \pm 26.66 \mathrm{~m}^{2}$; own scent: $226.62 \pm 31.76 \mathrm{~m}^{2}$ ), and not significantly different (LMM and Tukey HSD; all P > 0.73). Similarly, when considering the kin group only, we found no significant differences in the areas covered by females during the 30-min observation between the no-scent and scent condition, regardless of whether the scent originated from a daughter $\left(\mathrm{LMM}\right.$; estimate $=-47.03 ; \mathrm{CI}_{95}=[-243.48$, 
$505140.41], t=-0.49, P=0.62)$, a mother (estimate $=32.79 ; \mathrm{CI}_{95}=[-124.72,190.31], t=0.41, P$

$506=0.68)$, or a littermate sister $\left(\right.$ estimate $\left.=132.25 ; \mathrm{CI}_{95}=[-24.47,288.97], t=1.65, P=0.10\right)$

507 (Fig 5b). Here also, on average, the area covered by females was similar for all 3 groups 508 (daughter scent: area $=232.52 \pm 52.21 \mathrm{~m}^{2}$; mother scent: $199.80 \pm 40.65 \mathrm{~m}^{2}$; sister scent: $509269.56 \pm 43.54 \mathrm{~m}^{2}$ ), and not significantly different (LMM and Tukey HSD; all P > 0.62).

Distance to nest burrows

512 Controlling for age, the distance a female travelled from her nest burrow generally increased 513 in a non-linear fashion in all groups over the 30-minute observation period (GAMMs; $2.30<$ $514 e d f<4.69,10.00<F<46.80$, all $\mathrm{P}<0.001$; Fig 6). In all groups and treatments, females

515 rapidly distanced themselves from their nest burrow upon emergence, reaching 10m within 516 the first 9-10 minutes of observation. The distance from the nest increased more 517 progressively (or plateaued out) after that. The overall overlap between 95\% CI suggested no 518 marked difference between experimental conditions (with or without scent) (Fig 6). 519 Interestingly however, in the mother and sister scent group, females tended to travel further 520 from their nest burrows towards the end of the observation period when the scent was present 521 compared to the no-scent condition.

\section{Physiological stress}

\section{Fecal cortisol metabolites (FCMs)}

525 In response to the scent application, controlling for age, females exhibited a significant $36 \%$ 526 increase in FCM levels when exposed to their own scent compared to the no scent condition 527 (LMM; estimate $=747.5 \pm 301.0, t=2.48, P=0.03$; Fig 7A). No significant change was 528 observed in the two other conditions (kin scent: estimate $=513.7 \pm 327.6, t=1.57, P=0.14$; 529 unfamiliar female scent: estimate $=557.5 \pm 277.7, t=2.01, P=0.07)($ Fig 7A). Within kin 
categories, females exhibited $118 \%$ higher FCM when exposed to the scent of their mother

531 (Exact permutation test; $P=0.07)$, but not when exposed to the scent of a sister $(P=0.78)$ or

532 their daughter $(P=0.34)($ Fig $7 \mathrm{~B})$.

534 Plasma cortisol

535 In response to kin scents, controlling for age, females showed a significant $39 \%$ increase in 536 total cortisol levels $(\mathrm{LM}$; estimate $=38.17 \pm 15.42, t=2.47, P=0.02$, Fig 8A). Their MCBC 537 levels (Fig 8B) did not differ significantly from the control levels (LM; estimate $=1.54 \pm$ $53810.85, t=0.14, P=0.89$ ), resulting in a $35 \%$ (non-significant) increase in free cortisol levels $539(\mathrm{LM}$; estimate $=0.89 \pm 1.10, t=0.81, P=0.43)$. However, in this treatment, one female had 540 inexplicably high free cortisol levels (over 4 standard deviations, sampling time $=2.82 \mathrm{~min}$ ) 541 (see Fig 8C). Once this data point was removed from the analyses, females showed a 542 significant $131 \%$ increase in free cortisol levels in the presence of kin-scented cubes

543 compared to the no scent control situation (LM; estimate $=1.91 \pm 0.55, t=3.47, P=0.002)$.

544 Own-scent and unfamiliar female-scent categories did not differ significantly between control 545 and scented cubes in terms of total cortisol (LMMs; own scent: estimate $=12.84 \pm 15.33, t=$ $5460.83, P=0.42$; unfamiliar female scent: estimate $=2.30 \pm 9.59, t=0.24, P=0.81), \mathrm{MCBC}$ 547 (LMMs; own scent: estimate $=-0.83 \pm 12.43, \mathrm{t}=-0.07, \mathrm{P}=0.95$; unfamiliar female scent: 548 estimate $=-23.63 \pm 14.64, t=-1.61, P=0.12)$, or free cortisol $($ LMMs; own scent: estimate $=$ $5490.69 \pm 0.60, t=1.17, P=0.26$; unfamiliar female scent: estimate $=0.48 \pm 0.29, t=1.65, P=$ $550 \quad 0.12)$.

Within kin (Fig 8, D-E), controlling for age, female total plasma cortisol levels 552 increased by $76 \%$ when they were exposed to the scent of their mother (Exact permutation 553 test; $\mathrm{P}=0.03)$, but not to the scent of a sister $(\mathrm{P}=0.10)$ or a daughter $(\mathrm{P}=0.84)($ Fig $8 \mathrm{D})$. MCBC levels did not differ significantly between control (unscented cubes) and treated 
555 (scented cubes) situations for either group (Exact permutation tests; $0.23<\mathrm{P}<0.91$ ) (Fig

556 8E). As a result, females exhibited a significant $318 \%$ increase in free cortisol levels in 557 response to the scent of their mother (Exact permutation test; $\mathrm{P}=0.002$ ) once the outlier was 558 removed (24\% with the outlier) (Fig 8F). Free cortisol levels did not differ significantly 559 between control and treated cubes for daughter or sister scents (Exact permutation tests; 0.09 $560<\mathrm{P}<0.54)($ Fig 8E).

561

\section{DISCUSSION}

563 Resident female Columbian ground squirrels were highly sensitive to the scent marks of other

564 lactating females deposited next to their nest burrows, exhibiting overall increases both in 565 vigilance behavior and baseline glucocorticoid levels compared to control conditions (i.e., the 566 absence of scents, or the presence of the female's own scent). Our results suggest that scent 567 marking of both familiar and unfamiliar animals around the nest burrows of focal females

568 was stressful, leading to increased vigilance behavior and heightened HPA axis activity 569 (higher baseline cortisol levels). Lactating females did not significantly increase or decrease 570 space use in response to the treatment, suggesting they did not actively seek-out simulated 571 intruders by increasing exploration behavior on their territories, nor did they remain close to 572 their nest burrow to defend offspring. This is somewhat surprising since female ground 573 squirrels exclude conspecifics forcefully from around their nest burrows, although daily 574 foraging home ranges overlap substantially (e.g., Murie and Harris 1988; King 1989; Arnaud 575 et al. 2012). However, lactating females significantly increased the proportion of time spent 576 in vigilance behavior compared to foraging or other behavioral categories, both when 577 exposed to unfamiliar or kin scents, but not when exposed to their own scent. Contrary to our 578 expectation, females were more vigilant in the presence of kin female scents on their 579 territories than the scents of unfamiliar females. For example, females presented with kin 
scents had $42 \%$ points higher odds of engaging in vigilance rather than foraging, than females

581 presented with unfamiliar scents. The increase in vigilance towards kin was mirrored in the

582 stress axis: females experienced a significant $131 \%$ increase in plasma free cortisol levels

583 (but not FCMs) compared to the no-scent condition when exposed to kin scents, but not when

584 exposed to unfamiliar or their own scents. The presence of an unfamiliar individual near a

585 female's nest burrow should also be a stressful event, especially since female ground 586 squirrels are more tolerant of kin than unrelated individuals (King 1989a; Viblanc et al. 2016). Yet, neither FCM nor free cortisol levels were increased by our treatment that introduced the scents of potentially dangerous strangers. Given that vigilance was 589 significantly increased by the same treatment, it seems that evidence of foreign individuals is 590 acknowledged by increased observance, but without an associated increase in stress. The 591 presence of close relatives, by comparison, is a more stressful situation.

593 unfamiliar female scents is surprising. The "dear-enemy" hypothesis proposes that territory 594 holders should react more strongly to unknown tentative usurpers than to territorial neighbors 595 of known resource holding potential (e.g., Fisher 1954; Temeles 1994; Christiansen and 596 Radford 2018). At first glance, our results might appear to reject the "dear enemy" 597 hypothesis, since unfamiliar female scents were collected on neighboring meadows, and were 598 therefore foreign and novel stimuli to resident females (Hare 1994). However, resident 599 females also interacted more (licking, sniffing or attacking) with unfamiliar-scented than kin600 scented cubes, suggesting that they were more responsive to novel than familiar scents (see 601 also Raynaud \& Dobson 2011), as would be predicted by the "dear-enemy" hypothesis. In 602 addition, previous studies have found that female Columbian ground squirrels are less 603 aggressive toward their female kin than unrelated individuals (King 1989a; Viblanc et al. 604 2016). Thus, one explanation of our results is that lactating females may have a fine 
605 knowledge of the territorial boundaries of their close female kin. They treat markings of 606 relatives on their territories as territorial shifts, and evaluate those as a greater threat (as 607 evidenced by increased glucocorticoid levels) than the scents of female squirrels not 608 recognized as direct neighbors.

609 An alternative explanation may be that heightened HPA axis activity in response to 610 close kin scents occurs as resident females prepare for increased metabolic activity associated 611 with cooperation among relatives (Soares et al. 2010; but see Santema et al. 2013). Although 612 Columbian ground squirrels are not known to engage into active cooperation, close kin are 613 more tolerant of one-another (King 1989a; Viblanc et al. 2016), and kin females may engage 614 in chasing intruders together at the border of adjacent territories (VAV, personal 615 observations). In addition, our study used unfamiliar scents from females that originated in 616 other populations. Yet, familiar scents from known non-kin female neighbors inhabiting the 617 same colony may well prove more stressful than kin scents, a hypothesis that remains to be 618 tested. In line with this idea, juvenile Columbian ground squirrels show similar levels of 619 cohesive and agonistic behavior, and similar interindividual distances in staged dyadic 620 interactions with conspecific juvenile colony members, but decreased cohesion, increased agonism, and greater inter-individual distances in staged interactions with juvenile conspecifics from neighbouring colonies (Hare 1992). In the presence of artificial scent marks that mimicked territorial intrusions, the 624 absence of territorial scent marking by lactating females might indicate that core territories of 625 these females were already sufficiently saturated with their scent. Alternatively, if a female's 626 scent were concentrated near her nest burrow, it might serve as an attractant to potential 627 perpetrators of infanticide (Balfour 1983; Dobson 1990; Hare 1991; Stevens 1998). Females 628 are indeed known to conceal their nest burrows by plugging them with soft soil and litter, 629 possibly to deter infanticial conspecifics (McLean 1978). This might explain why female 
630 cortisol levels generally increased when their own scent was experimentally introduced 631 around their nest burrows (compared to the no-scent situation), divulging their secretive 632 location.

633 Interestingly, different kin scents elicited different reactions from resident females.

634 Lactating resident females were most vigilant to the scent of their sisters, then daughters, and 635 finally mothers. Surprisingly, however, the stress axis told a different story. Females reacted strongly to the scent of their mothers, but not to that of their daughters or sisters. They exhibited a significant $318 \%$ increase in free cortisol levels when exposed to their mother's scent compared to the no-scent condition, and a $118 \%(P=0.06)$ increase in FCM levels.

639 Thus, whereas lactating females were more vigilant towards sisters' scents, their stress was 640 actually higher when presented with mother scents. Mothers are known to behave cohesively to yearling daughters, but aggressively to yearling immigrants, when resources were not

642 limiting (Wigget \& Boag 1992). Relinquishment of breeding sites occurs in favor of yearling 643 daughters (Harris \& Murie 1984). Because mothers favor the establishment of yearling (but 644 not older) daughters (Neuhaus et al. 2004), it is possible that the scent of a mother is 645 perceived as a potential threat to an older daughter because of the possibility of a mother 646 relinquishing a former territory to a yearling daughter. The glucocorticoid differences found 647 here are consistent with our previous findings (Sosa et al. 2020): when compared to females 648 that had no co-breeding kin present in the population, lactating female having only a daughter 649 or a sister present in the population showed decreased FCM levels, whereas females having 650 only their mother presented similarly elevated FCM levels as females having no close kin around.

To our knowledge, surprisingly few studies have investigated the effects of scent 653 marking on receivers' stress physiology in territorial species. In solitary blind mole rats 654 (Spalax ehrenbergi), long-term exposure to scent-marks of intruders resulted in 
hypoglycemia, increased neutrophil/lymphocyte ratios, and partial ulceration of the liver and spleen, ultimately leading to death (Zuri et al. 1998). These effects were clearly indicative of over-activation of the adrenal function, impaired immunity, and chronic stress (Zuri et al. 1998; see review by Davis et al. 2008). Interestingly, in solitary blind mole rats, it is

659 specifically the long-term exposure to scents that was associated with increased mortality rates. This may indicate how profound the effects of scent-induced social stress may be when territory owners cannot retreat from scents, chase-away territory usurpers, or shift territories in response to intruders. Our study used an acute 30-min exposure to invader scents in a

663 territorial species, and the stress response in terms of glucocorticoid secretion and HPA axis 664 activation was substantial over this short time period. Whether longer exposure to scents 665 might result in chronic stress in our species, or cause females to shift territories, remains to be tested. Nonetheless, it appears clear that, besides encoding specific information on the identity of the donor, social scent communication via territorial marking had pronounced

668 effects on the receiver's behavior and physiology. We suggest that integrating the olfactory 669 landscape related to social stress together with predation risk within "the ecology of fear" 670 concept (Clinchy et al. 2013) should prove valuable to a proper understanding of behavioral and physiological consequences of habitat choice in territorial species.

\section{ACKNOWLEDGMENTS}

675 We are grateful to M. Holmes and P.D. Edwards for inviting us to contribute to this special issue, and to J.F. Hare and an anonymous reviewer for constructive and helpful comments on

677 the paper. We are grateful to Alberta Parks, and Alberta Environment, Fish \& Wildlife for 678 granting us access to the study sites and support with the long-term research. The University 679 of Calgary Biogeoscience Institute provided housing at the R. B. Miller field station during 
data collection in Sheep River Provincial Park (AB, Canada). We are especially grateful to E. for providing us with field camp and laboratory facilities, and to K. Rucktuhl for her

683 continued support in the field. We thank F. Criscuolo for his help and helpful comments on 684 the manuscript. The IPHC-CNRS contributed to resources needed for data analysis. J. O.

685 Murie initiated the long-term study on Columbian ground squirrels and provided helpful 686 comments on the manuscript. As always, we are indebted for his continued advice and

687 friendly support in our endeavors.

688

689 COMPETING INTERESTS

690 The authors declare no competing or financial interests.

691

\section{FUNDING}

693 The research was funded by a CNRS Projet International de Coopération Scientifique grant 694 (PICS-07143) and a research grant from the Fondation Fyssen to V.A.V., by a USA National 695 Science Foundation grant (DEB-0089473) to F.S.D., and a fellowship grant from the Institute 696 of Advanced Studies of the University of Strasbourg to F.S.D. and V.A.V. F.S.D. thanks the 697 Région Grand Est and the Eurométropole de Strasbourg for the award of a Gutenberg 698 Excellence Chair.

699

\section{REFERENCES}

701 1. Apfelbach R, Blanchard CD, Blanchard RJ, Hayes RA, McGregor IS. 2005. The effects 702 of predator odors in mammalian prey species: A review of field and laboratory studies. $703 \quad$ Neurosci Biobehav Rev. 29(8):1123-1144.

704 2. Arnaud CM, Dobson FS, Murie JO. 2012. Philopatry and within-colony movements in 
705 Columbian ground squirrels. Mol Ecol. 21(3):493-504.

706 3. Balfour D. 1983. Infanticide in the Columbian ground squirrel, Spermophilus $707 \quad$ columbianus. Anim Behav. 31(3):949-950.

708 4. Bateson M, Martin P. 2021. Measuring behaviour: an introductory guide. Cambridge $709 \quad$ University Press.

710 5. Bel MC, Coulon J, Sreng L, Allainé D, Bagnères AG, Clément JL. 1999. Social signals involved in scent-marking behavior by cheek-rubbing in alpine marmots (Marmota marmota). J Chem Ecol. 25(10):2267-2283.

6. Betts BJ. 1976. Behaviour in a population of Columbian ground squirrels, Spermophilus columbianus columbianus. Anim Behav. 24(3):652-680.

715 7. Bosson CO, Palme R, Boonstra R. 2009. Assessment of the stress response in Columbian ground squirrels: laboratory and field validation of an enzyme immunoassay for fecal cortisol metabolites. Physiol Biochem Zool. 82(3):291-301.

8. Boulet M, Crawford JC, Charpentier MJE, Drea CM. 2010. Honest olfactory ornamentation in a female-dominant primate. J Evol Biol. 23(7):1558-1563.

9. Brady KM, Armitage KB. 1999. Scent-marking in the yellow-bellied marmot (Marmota flaviventris). Ethol Ecol Evol. 11(1):35-47.

10. Charpentier MJE, Boulet M, Drea CM. 2008. Smelling right: the scent of male lemurs advertises genetic quality and relatedness. Mol Ecol. 17(14):3225-3233.

724 11. Christensen C, Radford AN. 2018. Dear enemies or nasty neighbors? Causes and 725 consequences of variation in the responses of group-living species to territorial intrusions. Behav Ecol. 29(5):1004-1013.

12. Clinchy M, Sheriff MJ, Zanette LY. 2012. Predator-induced stress and the ecology of fear. Funct Ecol. 27(1):56-65.

729 13. delBarco-Trillo J, Sacha CR, Dubay GR, Drea CM. 2012. Eulemur, me lemur: the 
evolution of scent-signal complexity in a primate clade. Philos Trans R Soc B Biol Sci. 367(1597):1909-1922.

14. Davis AK, Maney DL, Maerz JC. 2008. The use of leukocyte profiles to measure stress in vertebrates: a review for ecologists. Funct Ecol. 22(5):760-772.

15. Dobson FS. 1990. Environmental influences on infanticide in Columbian ground 735 squirrels. Ethology. 84(1):3-14.

16. Dobson FS, Badry MJ, Geddes C. 1992. Seasonal activity and body mass of Columbian ground squirrels. Can J Zool. 70(7):1364-1368.

17. Dobson FS, Murie JO, Viblanc VA. 2020. Fitness estimation for ecological studies: an evaluation in Columbian ground squirrels. Front Ecol Evol. 8:216.

18. Ferris CF, Axelson JF, Shinto LH, Albers HE. 1987. Scent marking and the maintenance of dominant/subordinate status in male golden hamsters. Physiol Behav. 40(5):661-664.

19. Ferron J, Ouellet J-P. 1989. Behavioural context and possible function of scent marking by cheek rubbing in the red squirrel (Tamiasciurus hudsonicus). Can J Zool. 67(7):16501653.

20. Fletcher QE, Boonstra R. 2006. Do captive male meadow voles experience acute stress in response to weasel odour? Can J Zool. 84(4):583-588.

21. Gosling LM, Roberts SC. 2001. Scent-marking by male mammals: Cheat-proof signals to competitors and mates. In: Advances in the Study of Behavior. vol 30, Academic Press.

22. p. 169-217.

23. Hare JF. 1991. Intraspecific killing of preweaned young in the Columbian ground squirrel, Spermophilus columbianus. Can J Zool. 69(3):797-800.

24. Hare JF. 1994. Group member discrimination by Columbian ground squirrels via familiarity with substrate-borne chemical cues. Anim Behav. 47(4):803-813. 
Columbian ground squirrels. Anim Behav. 30(1):140-148.

756

757

758

759

760

761

762

763

764

765

766

767

768

769

770

771

772

773

774

775

776

777

778

779

26. Harris MA, Murie JO. 1984. Inheritance of nest sites in female Columbian ground squirrels. Behav. Ecol. Sociobiol. 15: 97-102.

27. Harris MA, Murie JO. 1984. Discrimination of oestrous status by scent in Columbian ground squirrels. Anim Behav. 32(3):939-940.

28. Hurst JL, Rich TJ. 1999. Scent marks as competitive signals of mate quality. In: Advances in Chemical Signals in Vertebrates. Boston, MA: Springer US. p. 209-225.

29. Johansson BG, Jones TM. 2007. The role of chemical communication in mate choice. Biol Rev. 82(2):265-289.

30. Johnson RP. 1973. Scent marking in mammals. Anim Behav. 21(3):521-535.

31. Johnston RE. 2003. Chemical communication in rodents: From pheromones to individual recognition. J Mammal. 84(4):21.

32. Jojola SM, Rosell F, Warrington I, Swenson JE, Zedrosser A. 2012. Subadult brown bears (Ursus arctos) discriminate between unfamiliar adult male and female anal gland secretion. Mamm Biol. 77(5): 363-368.

33. Kean EF, Müller CT, Chadwick EA. 2011. Otter scent signals age, sex, and reproductive status. Chem Senses. 36(6):555-564.

34. King, WJ. 1989. Spacing of female kin in Columbian ground squirrels (Spermophilus columbianus). Can J Zool. 67(1):91-95.

35. King ,WJ. 1989. Kin-differential behaviour of adult female Columbian ground squirrels. Anim Behav. 38(4):354-356.

36. King WJ, Murie JO. 1985. Temporal overlap of female kin in Columbian ground squirrels (Spermophilus columbianus). Behav Ecol Sociobiol. 16(4):337-341.

37. Kivett VK. 1978. Integumentary glands of Columbian ground squirrels (Spermophilus columbianus): Sciuridae. Can J Zool. 56(3):374-381. 
38. Kivett VK, Murie JO, Steiner AL. 1976. A comparative study of scent-gland location and related behaviour in some northwestern nearctic ground squirrel species (Sciuridae): an evolutionary approach. Can J Zool. 54(8):1294-1306.

39. Leclaire S, Nielsen JF, Thavarajah NK, Manser M, Clutton-Brock TH. 2013. Odourbased kin discrimination in the cooperatively breeding meerkat. Biol Lett. 9(1):20121054.

40. López P, Martín J. 2005. Female Iberian wall lizards prefer male scents that signal a better cell-mediated immune response. Biol Lett. 1(4):404-406.

41. Lumley L., Sipos M., Charles R., Charles R., Meyerhoff J. 1999. Social stress effects on territorial marking and ultrasonic vocalizations in mice. Physiol Behav. 67(5):769-775.

42. Manno TG, Dobson FS. 2008. Why are male Columbian ground squirrels territorial? Ethology. 114(11):1049-1060.

43. Mateo JM. 2003. Kin Recognition in Ground Squirrels and Other Rodents. J Mammal. 84(4):1163-1181.

44. Mateo JM. 2006. The nature and representation of individual recognition odours in Belding's ground squirrels. Anim Behav. 71(1):141-154.

45. Mateo JM. 2009. The causal role of odours in the development of recognition templates and social preferences. Anim Behav. 77(1): 115-121.

46. McLean IG. 1978. Plugging of nest burrows by female Spermophilus columbianus. J Mammal. 59(2): 437-439.

47. Monclús R, Rödel HG, Palme R, Holst D Von, Miguel J de. 2006. Non-invasive measurement of the physiological stress response of wild rabbits to the odour of a predator. Chemoecology. 16(1):25-29.

48. Murie JO. 1995. Mating behavior of Columbian ground squirrels. I. Multiple mating by females and multiple paternity. Can J Zool. 73(10):1819-1826.

49. Murie JO, Harris MA. 1978. Territoriality and dominance in male Columbian ground 
squirrels (Spermophilus columbianus). Can J Zool. 56(11):2402-2412.

806

807

808

809

810

811

812

813

814

815

816

817

818

819

820

821

822

823

824

825

826

827

828

829

50. Neuhaus P, Broussard D, Murie J, Dobson FS. 2004. Age of primiparity and implications of early reproduction on life history in female Columbian ground squirrels. J Anim Ecol 73:36-43

51. Neuhaus P. 2006. Causes and consequences of sex-biased dispersal in Columbian ground squirrel, Spermophilus columbianus. Behaviour. 143(8):1013-1031.

52. Ouellet J-P, Ferron J. 1988. Scent-marking behavior by woodchucks (Marmota monax). J Mammal. 69(2):365-368.

53. Radwan J, Chadzińska M, Cichoń M, Mills SC, Matuła B, Sadowska ET, Baliga K, Stanisz A, Łopuch S, Koteja P. 2006. Metabolic costs of sexual advertisement in the bank vole (Clethrionomys glareolus). Evol Ecol Res. 8:859-869.

54. Ralls K. 1971. Mammalian scent marking. Science. 171(3970):443-449.

55. Raveh S, Heg D, Dobson FS, Coltman DW, Gorrell JC, Balmer A, Neuhaus P. 2010. Mating order and reproductive success in male Columbian ground squirrels (Urocitellus columbianus). Behav Ecol. 21(3):537-547.

56. Raynaud J, Dobson SF. 2011. Scent communication by female Columbian ground squirrels, Urocitellus columbianus. Behav Ecol Sociobiol. 65(2):351-358.

57. Roberts SC. 1998. Behavioural responses to scent marks of increasing age in klipspringer Oreotragus oreotragus. Ethology, 104(7), 585-592.

58. Santema P, Teiltel Z, Manser M, Bennet N, Clutton-Brock T. 2013. Effects of cortisol administration on cooperative behavior in meerkat helpers. Behav. Ecol. 24(5):11221127.

59. Scordato ES, Drea CM. 2007. Scents and sensibility: information content of olfactory signals in the ringtailed lemur, Lemur catta. Anim Behav. 73(2):301-314.

60. Shimozuru M, T K, Takeuchi Y, Mori Y. 2006. Social-defeat stress suppresses scent- 
830 marking and social-approach behaviors in male Mongolian gerbils (Meriones 831 unguiculatus). Physiol Behav. 88(4-5):620-627.

832 61. Sillero-Zubiri C, Macdonald DW. 1998. Scent-marking and territorial behaviour of 833 Ethiopian wolves Canis simensis. J Zool. 245(3):351-361.

834 62. Soares MC, Bshary R, Fusani L, Goymann W, Hau M, Hirschenhauser K, Oliveira R. 835 2010. Hormonal mechanisms of cooperative behaviour. Phil. Trans. R. Soc. B. 365:2737 $836-2750$.

837 63. Sosa S, Dobson FS, Bordier C, Neuhaus P, Saraux C, Bosson C, Palme R, Boonstra R, 838 Viblanc VA. 2020. Social stress in female Columbian ground squirrels : density839 independent effects of kin contribute to variation in fecal glucocorticoid metabolites. $840 \quad$ Behav Ecol Sociobiol. 74:50

841 64. Steiner AL. 1970. Étude descriptive de quelques activités et comportements de base de 842 Spermophilus columbianus columbianus (Ord). II. Vie de groupe. Rev Comport Anim. $843 \quad 4: 23-42$.

844 65. Steiner AL. 1974. Body-rubbing, marking, and other scent-related behavior in some 845 ground squirrels (Sciuridae), a descriptive study. Can J Zool. 52(7):889-906.

846 66. Stevens SD. 1998. High incidence of infanticide by lactating females in a population of 847 Columbian ground squirrels (Spermophilus columbianus). Can J Zool. 76(6):1183-1187.

848 67. Stockley P, Bottell L, Hurst JL. 2013. Wake up and smell the conflict: Odour signals in 849 female competition. Philos Trans R Soc B Biol Sci. 368(1631):20130082.

850 68. Thonhauser KE, Raveh S, Hettyey A, Beissmann H, Penn DJ. 2013. Scent marking 851 increases male reproductive success in wild house mice. Anim Behav. 86(5): 1013-1021.

852 69. Vaglio S, Minicozzi P, Romoli R, Boscaro F, Pieraccini G, Moneti G, Moggi-Cecchi J. 853 2016. Sternal gland scent-marking signals sex, age, rank, and group identity in captive 854 mandrills. Chem Senses. 41(2):177-86. 
855 70. Viblanc VA, Pasquaretta C, Sueur C, Boonstra R, Dobson FS. 2016. Aggression in 856 Columbian ground squirrels: relationships with age, kinship, energy allocation, and 857 fitness. Behav Ecol. 27(6): 1716-1725.

858 71. Waterman JM, Archibald AJ. 2019. Both familiarity and kinship influence odour 859 discrimination by females in a highly social African ground squirrel. Anim Behav. $860 \quad 148: 145-151$.

72. Wedekind C, Seebeck T, Bettens F, Paepke AJ. 1995. MHC-dependent mate preferences in humans. Proc R Soc London Ser B Biol Sci. 260(1359):245-249.

73. Wheeler B, Torchiano M. 2016. lmPerm: permutation tests for linear models. R package version 2.1.0. https://CRAN.R-project.org/package=lmPerm

74. Wigget DR, Boag DA. 1992. The resident fitness hypothesis and dispesal by yearling 866 female Columbian ground squirrels. Can J Zool. 70: 1984-1994.

75. Wiggett DR, Boag DA. 1989. Intercolony natal dispersal in the Columbian ground squirrel. Can J Zool. 67(1):42-50.

869 76. Yamaguchi H, Kikusui T, Takeuchi Y, Yoshimura H, Mori Y. 2005. Social stress 870 decreases marking behavior independently of testosterone in Mongolian gerbils. Horm Behav. 47(5):549-555.

77. Zala SM, Potts WK, Penn DJ. 2004. Scent-marking displays provide honest signals of health and infection. Behav Ecol. 15(2):338-344.

78. Zidat T, Dufour A-B, Meiffren G, Gabirot M, Comte G, Allainé D. 2018. Anal scent 875 gland secretions inform on sexual maturity, sex and social status in the Alpine marmot, Marmota marmota (Rodentia: Sciuridae): a role in intrasexual competition in cooperative breeders? Biol J Linn Soc. 125(2):229-239.

79. Zuri I, Gottreich A, Terkel J. 1998. Social stress in neighboring and encountering blind mole-rats (Spalax ehrenbergi). Physiol Behav. 64(5):611-620. 


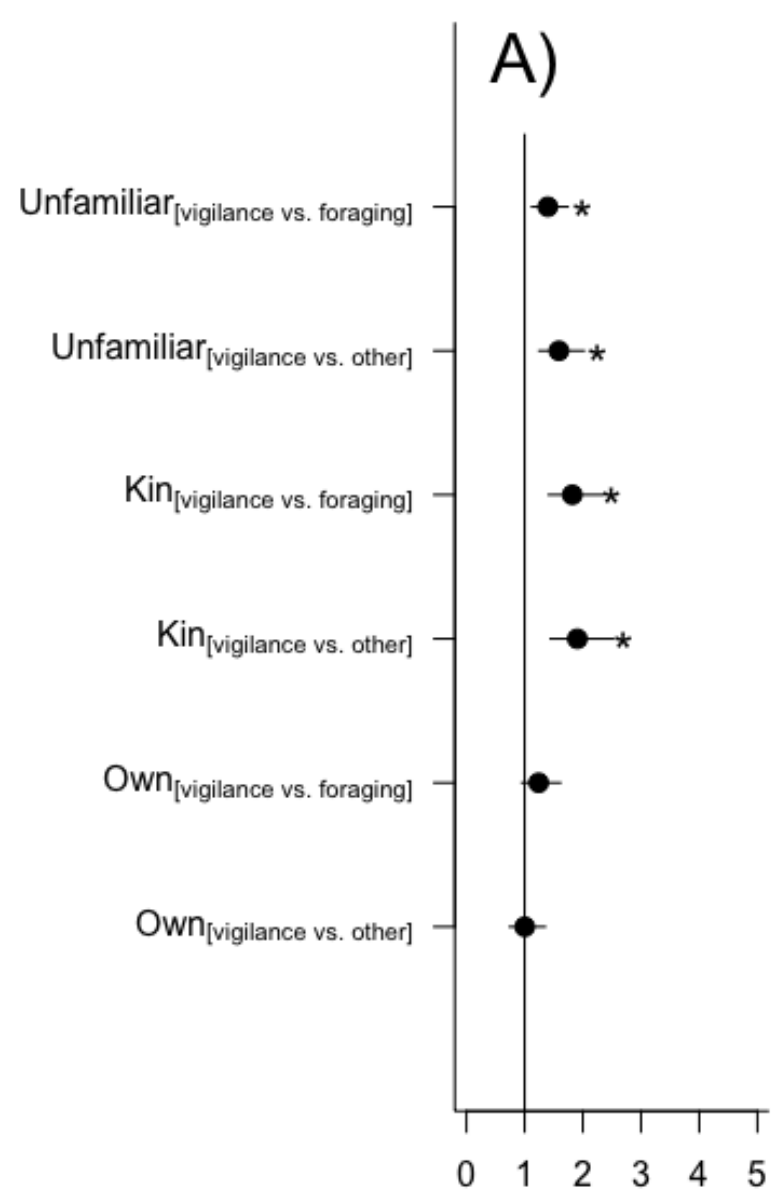

Odds ratio $\pm \mathrm{Cl}_{95 \%}$

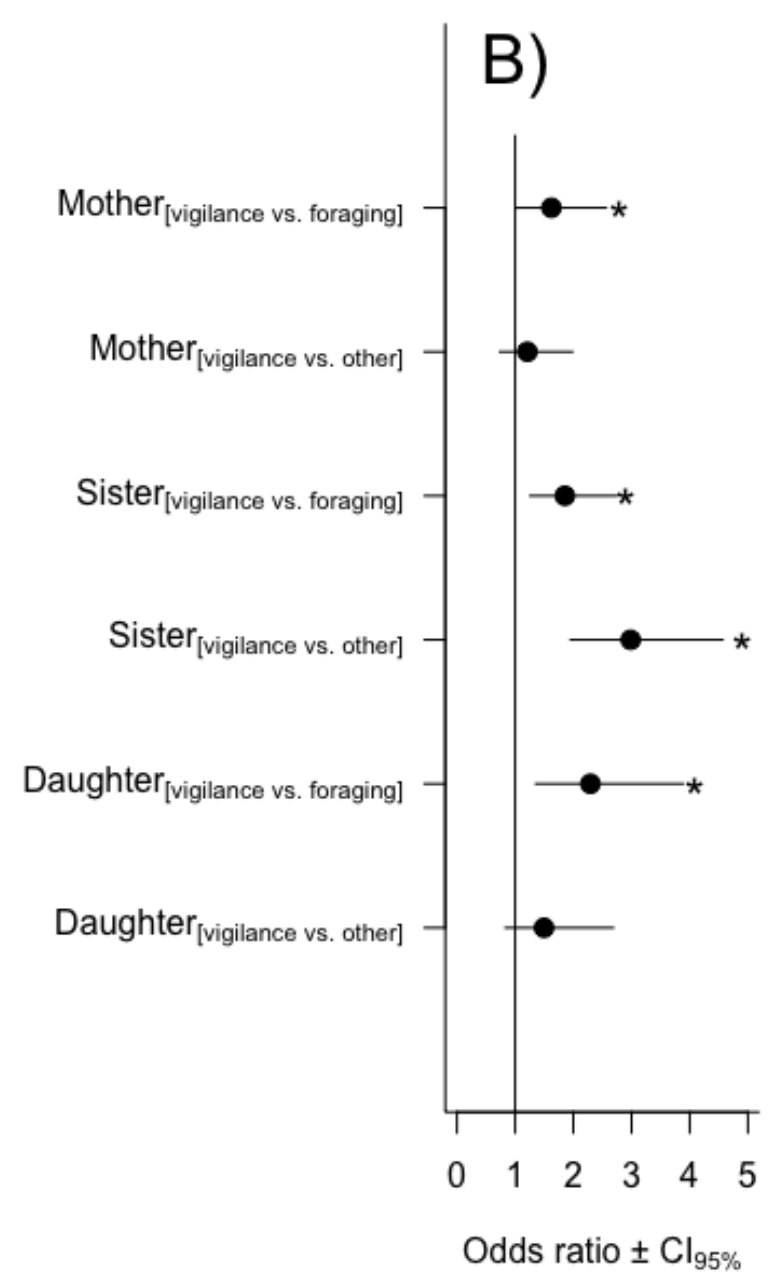

Fig 1. Changes in female vigilance behavior in reference to foraging or other behaviors during the 30-min observation period for female Columbian ground squirrels exposed to the scent of (A) an unfamiliar female, a kin female, or their own scent; and (B) within kin scents; the scent of their mother, a sister, or a daughter. Changes are expressed as odds ratio $\pm 95 \%$ CI. An odds ratio $>$ (or $<$ ) 1 indicates an increase (or a decrease) in vigilance behavior relative to foraging or other behaviors when a scent is presented. Significant changes occur for $95 \%$ CI not overlapping 1 and are indicated by an asterisk. 

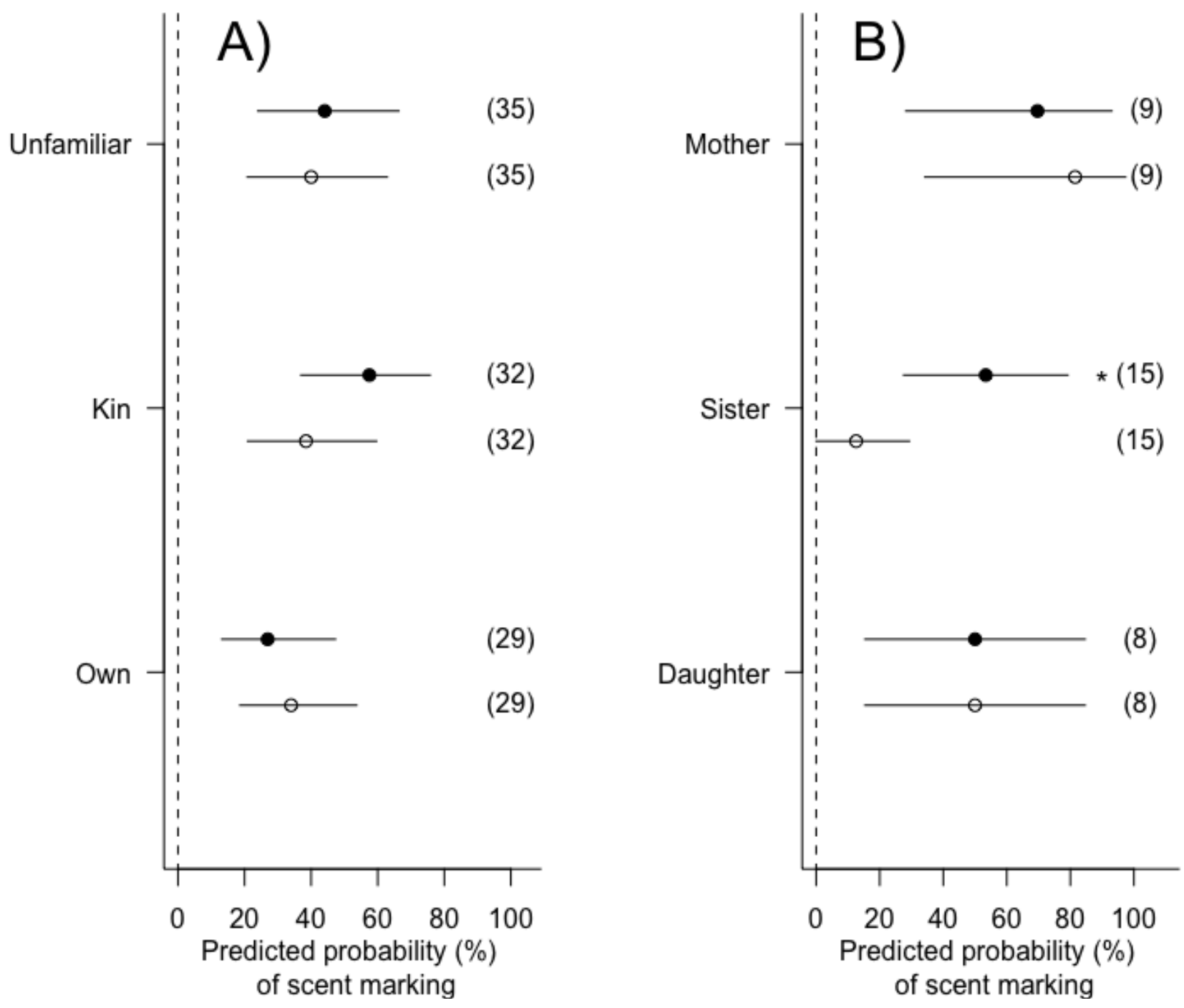

903 Fig 2. Probability of a female ground squirrel engaging in scent marking during the 30-min 904 observation period. Females were exposed to either no scent (o) or the scent $(\bullet)$ of (A) an 905 unfamiliar female, a kin female, or their own scent. (B) within kin scents; the scent of their 906 mother, a sister, or a daughter. Values are given as means $\pm 95 \%$ CI. Sample size is given in 907 brackets. Significant differences $(P<0.05)$ between $(\circ)$ and $(\bullet)$ conditions are indicated by an 908 asterisk.

909

910

911 

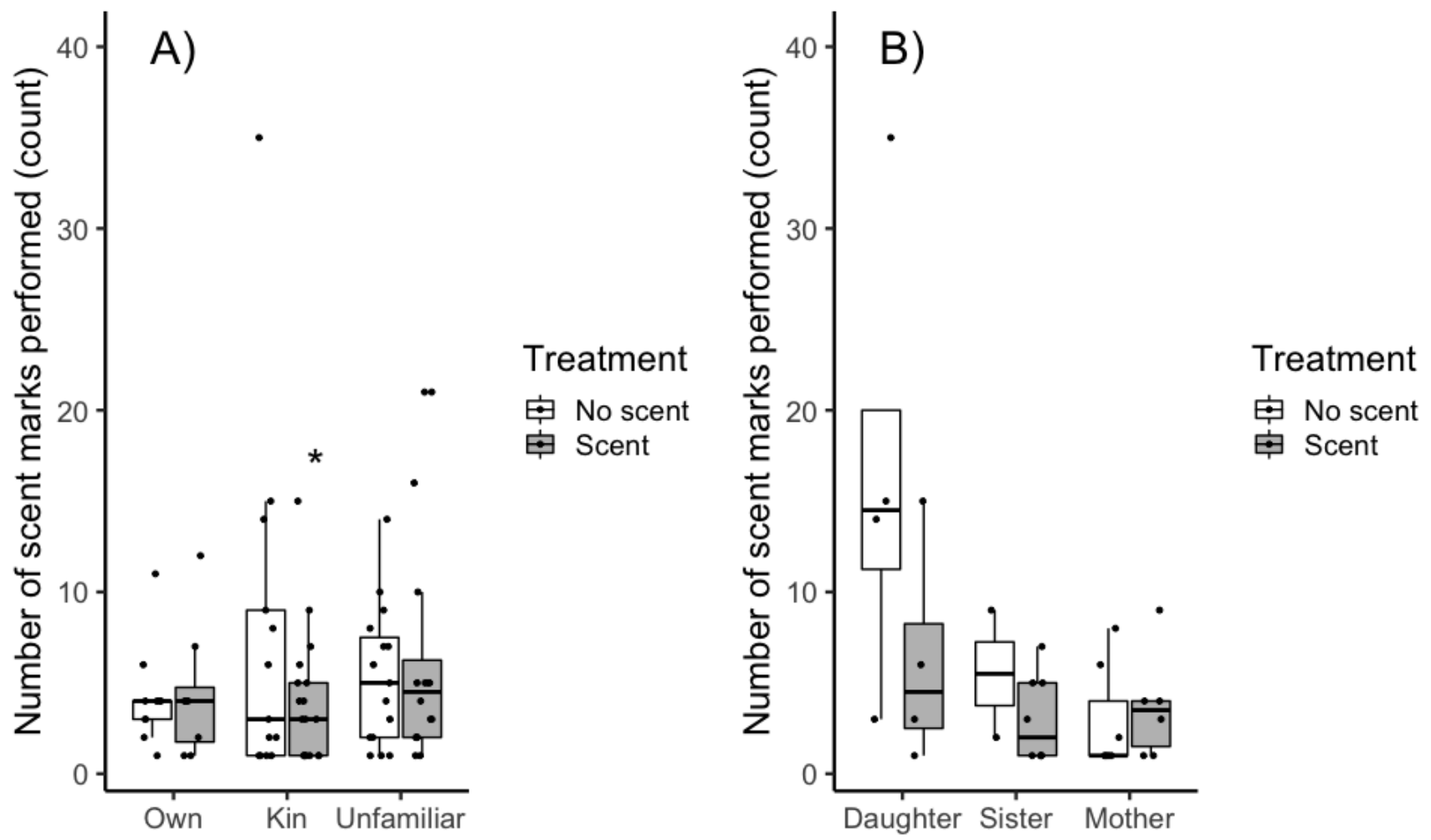

917 Fig 3. Number of scent marks deposited by a female ground squirrel during the 30-min 918 observation period. Females were exposed to either no scent (white boxplots) or the scent 919 (grey boxplots) of (A) an unfamiliar female, a kin female, or their own scent. (B) within kin 920 scents; the scent of their mother, a sister, or a daughter. Box plots show the median of the 921 data distribution (bold line) along with first and third quartiles ( $25^{\text {th }}$ and $75^{\text {th }}$ percentiles) of 922 the data distribution corresponding to the lower and upper hinges of the boxes. The upper and 923 lower whisker extend, respectively, to the largest and smallest value of the data set, no further 924 than 1.5 x IQR (where IQR is the inter-quartile range). Data beyond the end of the whiskers 925 are plotted individually. Significant differences $(P<0.05)$ between treatments are indicated 926 by an asterisk. Note that this statistically significant difference disappears when an outlier in 


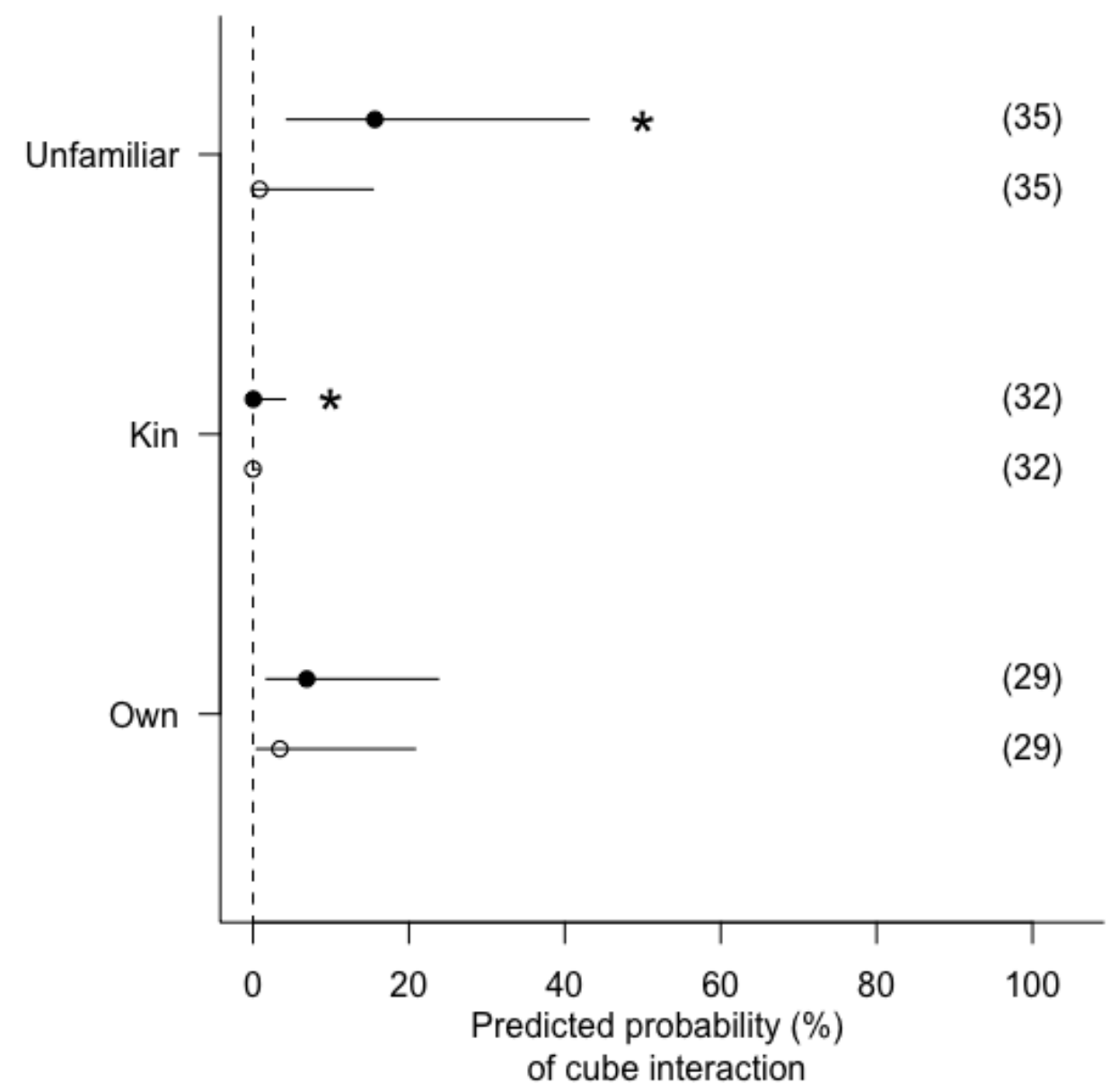

936 Fig 4. Probability of a female ground squirrel interacting with a scent cube during the 30-min 937 observation period. Females were exposed to either no scent ( $\circ$ ) or the scent (•) of an 938 unfamiliar female, a kin female, or their own scent. Values are given as means $\pm 95 \%$ CI. 939 Significant differences $(P<0.05)$ between $(\circ)$ and $(\bullet)$ conditions are indicated by an asterisk. 940 Sample size is given in brackets. 

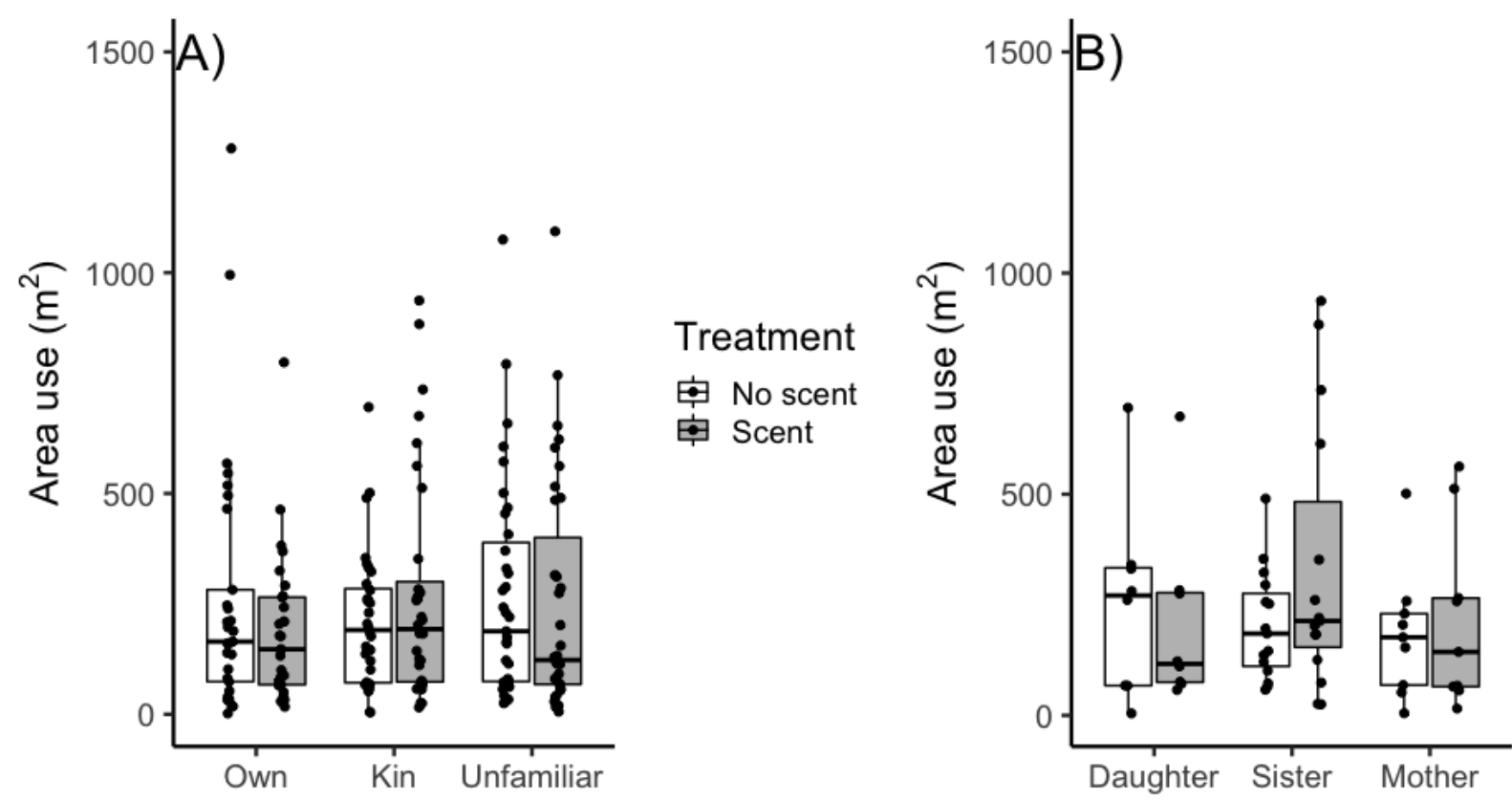

Fig 5. Area $\left(\mathrm{m}^{2}\right)$ covered over the 30 -min observation period by female Columbian squirrels. 946 The area was calculated from Cartesian coordinates recorded every minute, starting as soon as a female emerged from her nest burrow in the morning. Females were exposed to either no scent (white boxplots) or the scent (grey boxplots) of (A) an unfamiliar female, a kin female, or their own scent. (B) within kin scents; the scent of their mother, a sister, or a daughter. Box plots show the median of the data distribution (bold line) along with first and third quartiles $\left(25^{\text {th }}\right.$ and $75^{\text {th }}$ percentiles) of the data distribution corresponding to the lower and upper hinges of the boxes. The upper and lower whisker extend, respectively, to the largest and smallest value of the data set, no further than $1.5 \mathrm{x}$ IQR (where IQR is the inter-quartile range). Data beyond the end of the whiskers are plotted individually. 
OWN SCENT

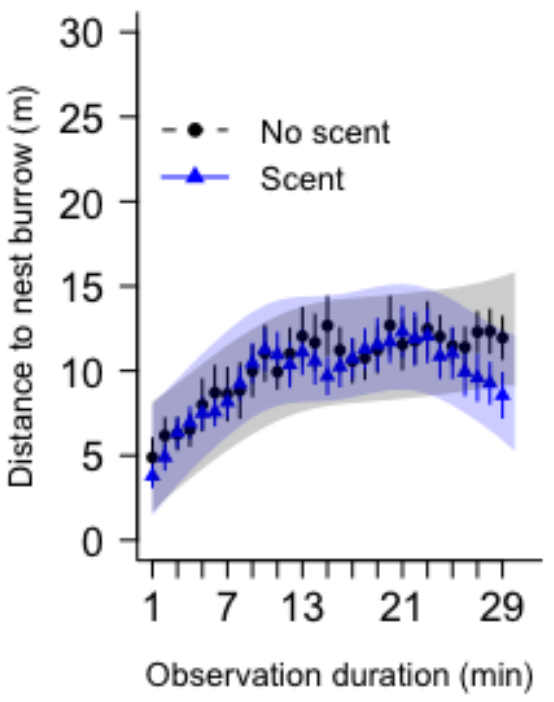

MOTHER SCENT

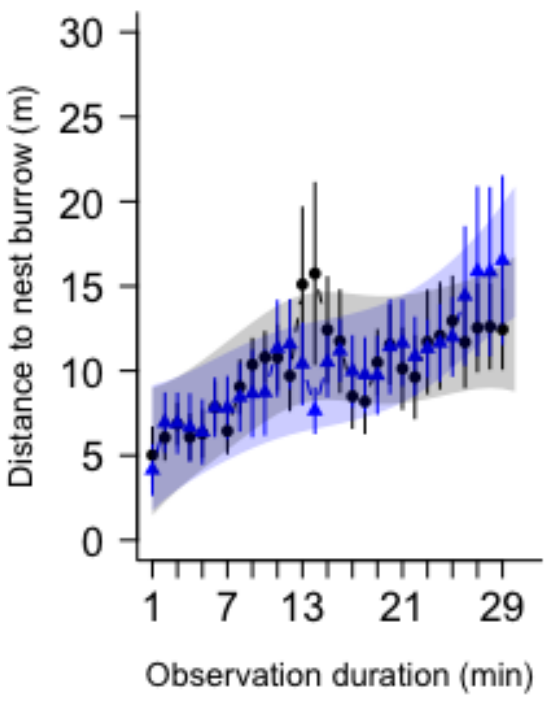

KIN SCENT

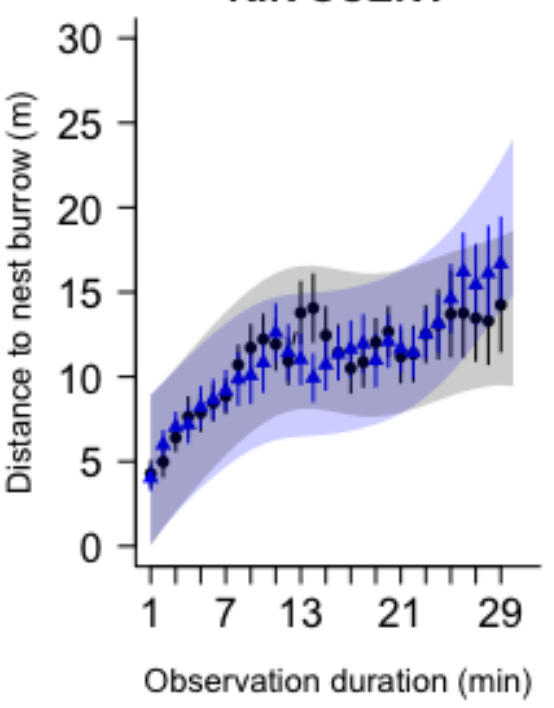

SISTER SCENT

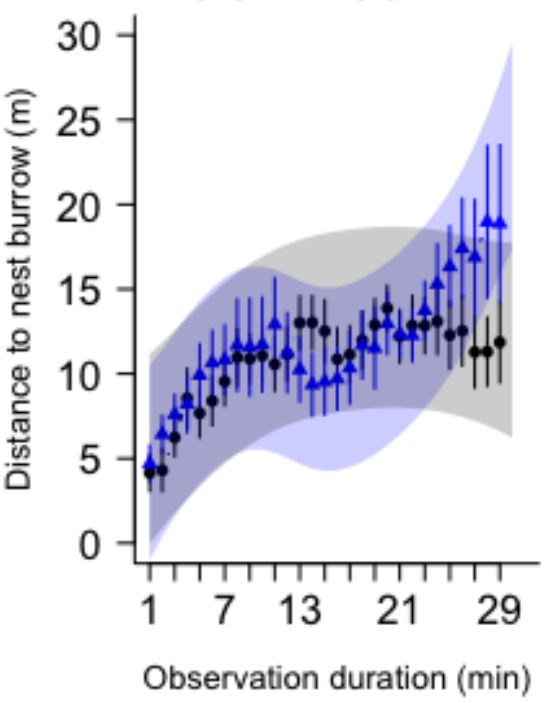

UNFAMILIAR SCENT

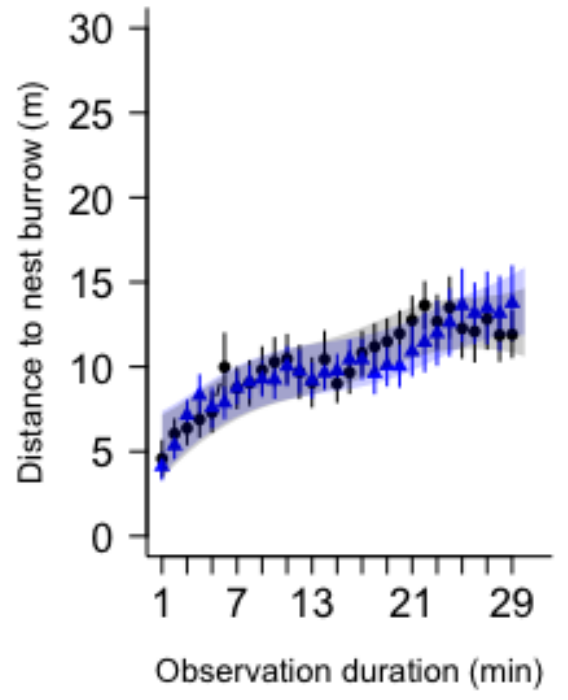

DAUGHTER SCENT

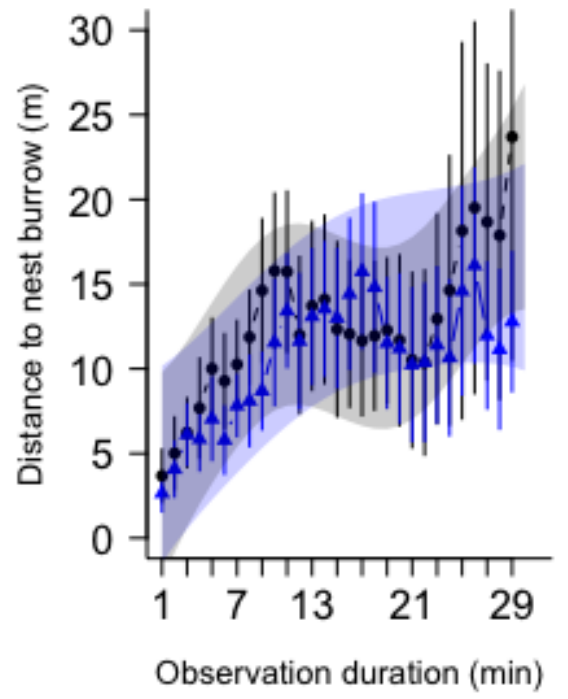

Fig 6. Distance of a female ground squirrel from her nest burrow at every minute of the 30min observation period. The distance was calculated from Cartesian coordinates recorded every minute, starting as soon as a female emerged from her nest burrow in the morning. Values are presented from minute 1 though 29 (minute 0 was the emergence from nest burrow, and the distance by definition $0 \mathrm{~m}$ ). Females were exposed to either no scent (black values) or the scent (blues values) of an unfamiliar female, a kin female, or their own scent (top row). Within the kin group, females were exposed to the scent of their mother, a littermate sister, or a daughter (bottom row). Values are given as means \pm SE. The grey and blue bands represent the $95 \%$ CI of the GAMMs. 

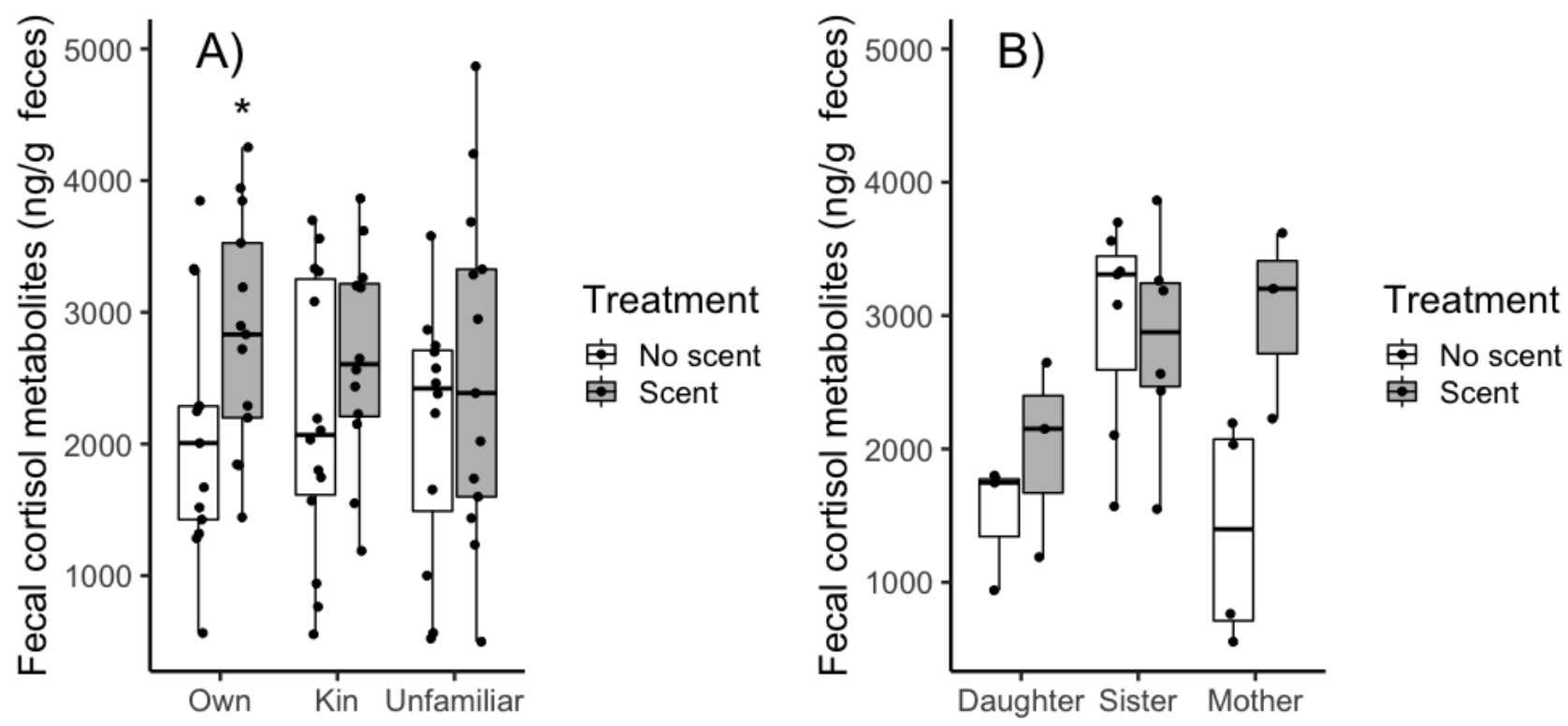

Fig 7. Fecal cortisol metabolite levels of female Columbian squirrels either exposed to no scent (white boxplots) or the scent (grey boxplots) of (A) an unfamiliar female, a kin female, 993 Box plots show the median of the data distribution (bold line) along with first and third quartiles $\left(25^{\text {th }}\right.$ and $75^{\text {th }}$ percentiles $)$ of the data distribution corresponding to the lower and upper hinges of the boxes. The upper and lower whisker extend, respectively, to the largest and smallest value of the data set, no further than 1.5 x IQR (where IQR is the inter-quartile range). Data beyond the end of the whiskers are plotted individually. Significant differences $(P<0.05)$ between the treatments are indicated by an asterisk. 


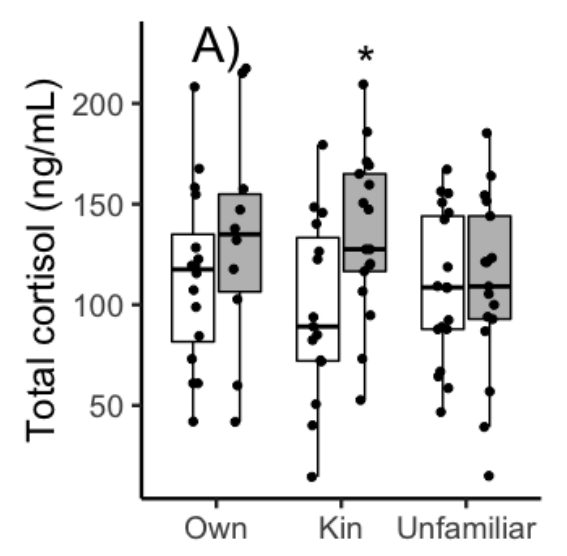

Treatment

审 No scent

审 Scent
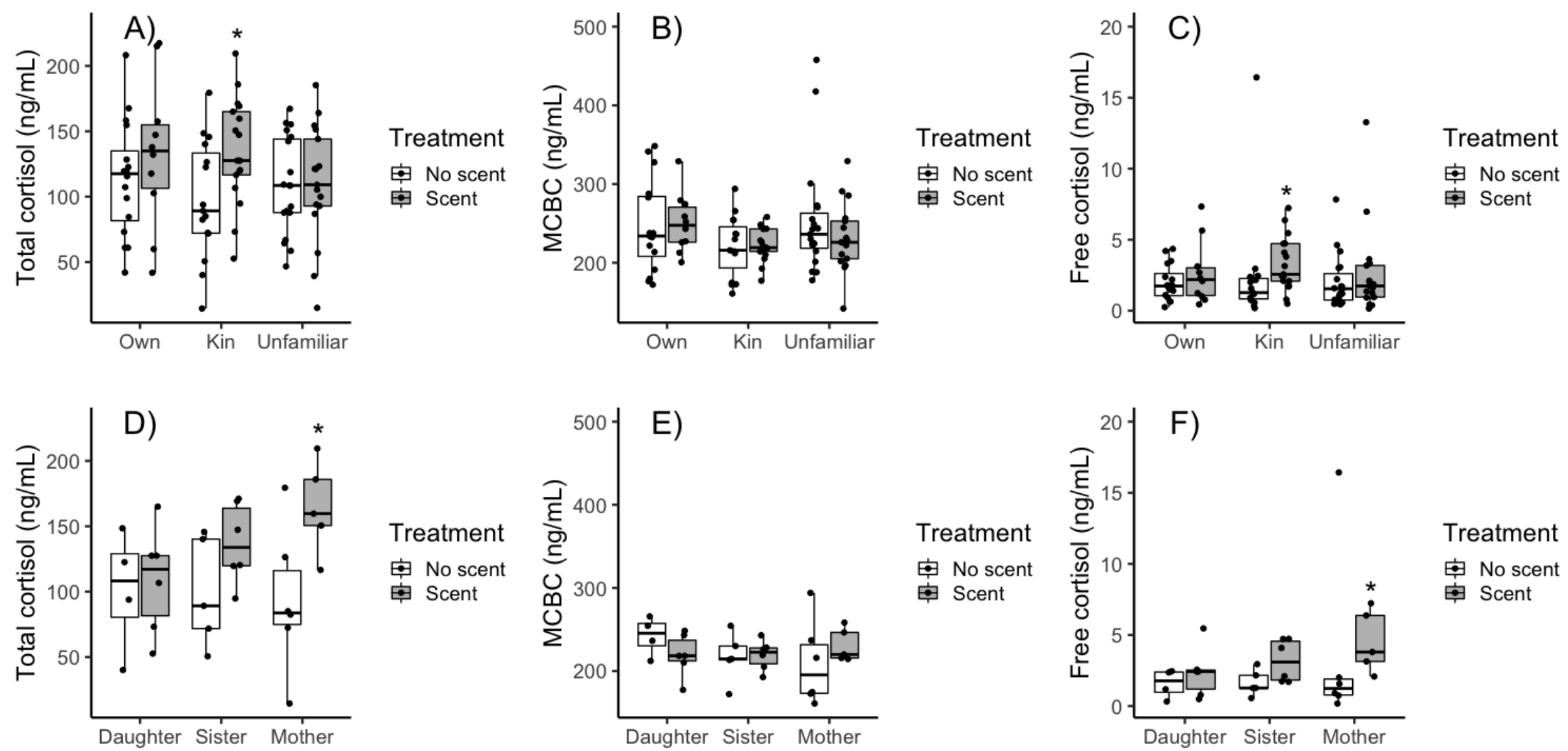

Fig 8. (A-C) Plasma levels of total cortisol (maximum cortisol binding capacity (MCBC) and free cortisol) of female Columbian squirrels exposed to no scent (white boxplots) or the scent (grey boxplots) of an unfamiliar female, a kin female or their own scent. (D-E) Within kin scents, plasma levels of total cortisol, MCBC and free cortisol after exposure to no scent or the scent of a daughter, a sister, or their mother. Box plots show the median of the data distribution (bold line) along with first and third quartiles $\left(25^{\text {th }}\right.$ and $75^{\text {th }}$ percentiles) of the data distribution corresponding to the lower and upper hinges of the boxes. The upper and lower whisker extend, respectively, to the largest and smallest value of 
the data set, no further than $1.5 \mathrm{x}$ IQR (where IQR is the inter-quartile range). Data beyond the end of the whiskers are plotted individually. 
1013 APPENDICES

1014

1015 Appendix 1 : Distribution of territorial scent marking and interactions with scent cubes 1016 during the 30 minute observation period for female Columbian ground squirrels

1017
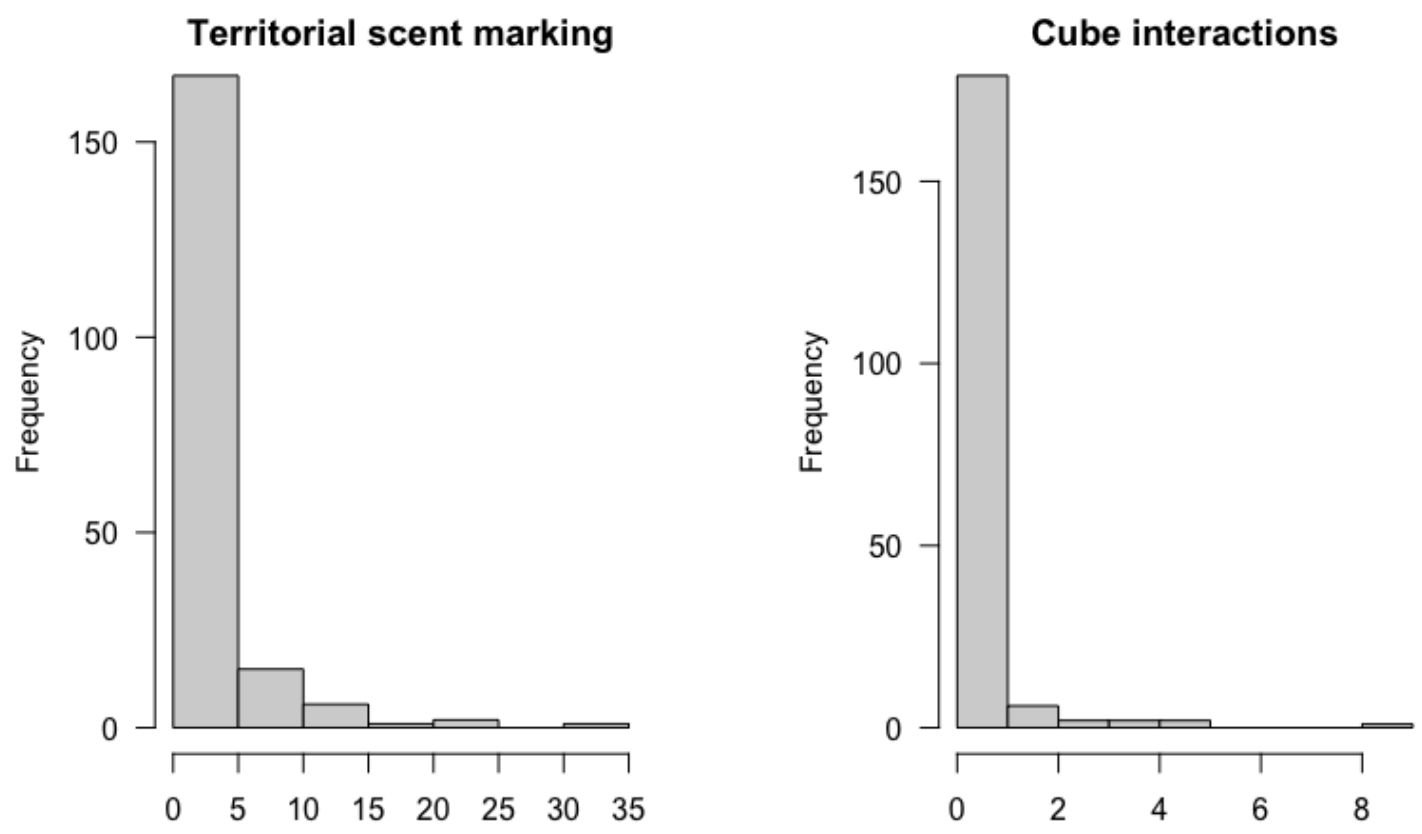
1020

1021

1022

1023

1024

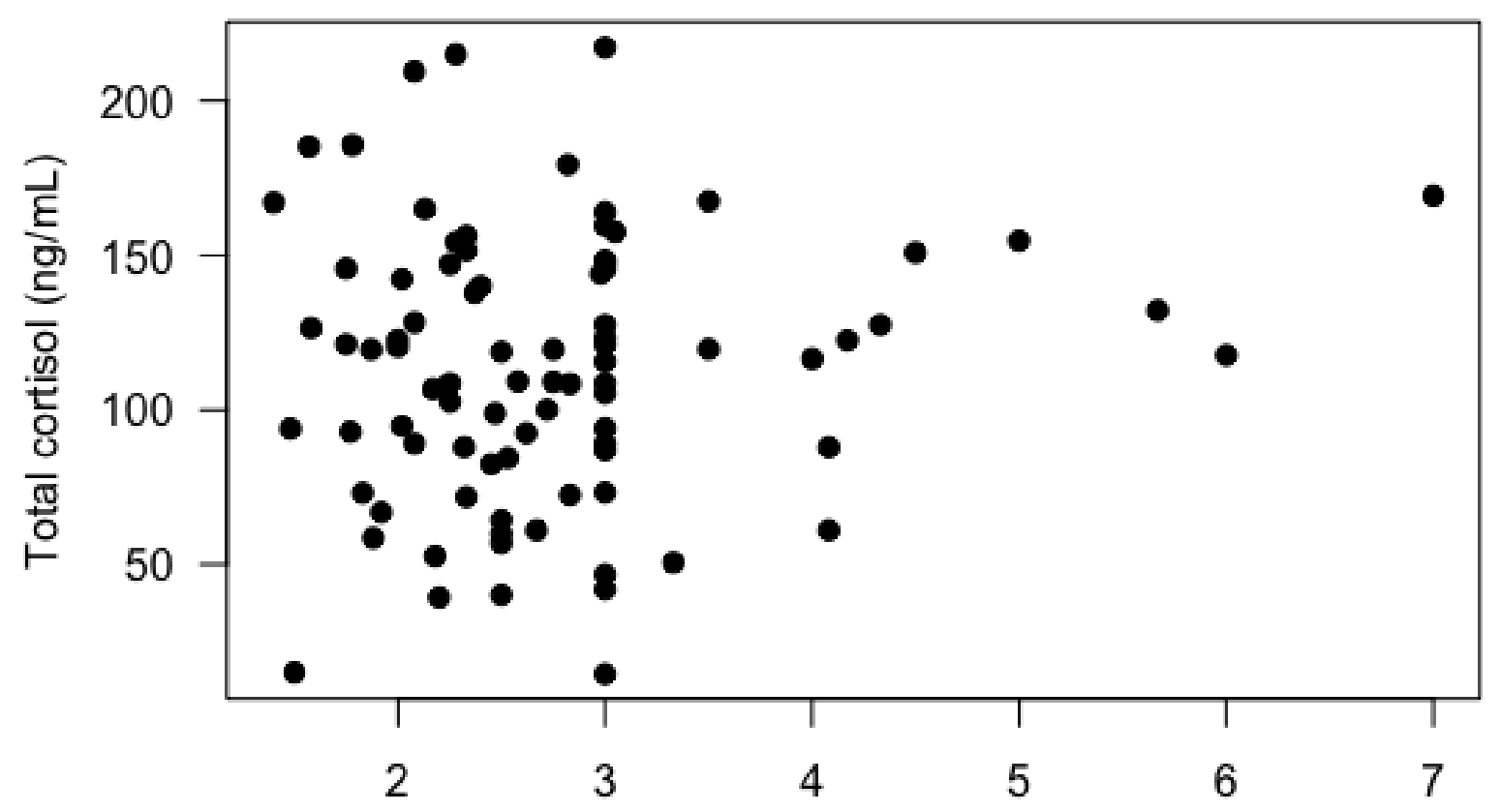

Sampling time (min)

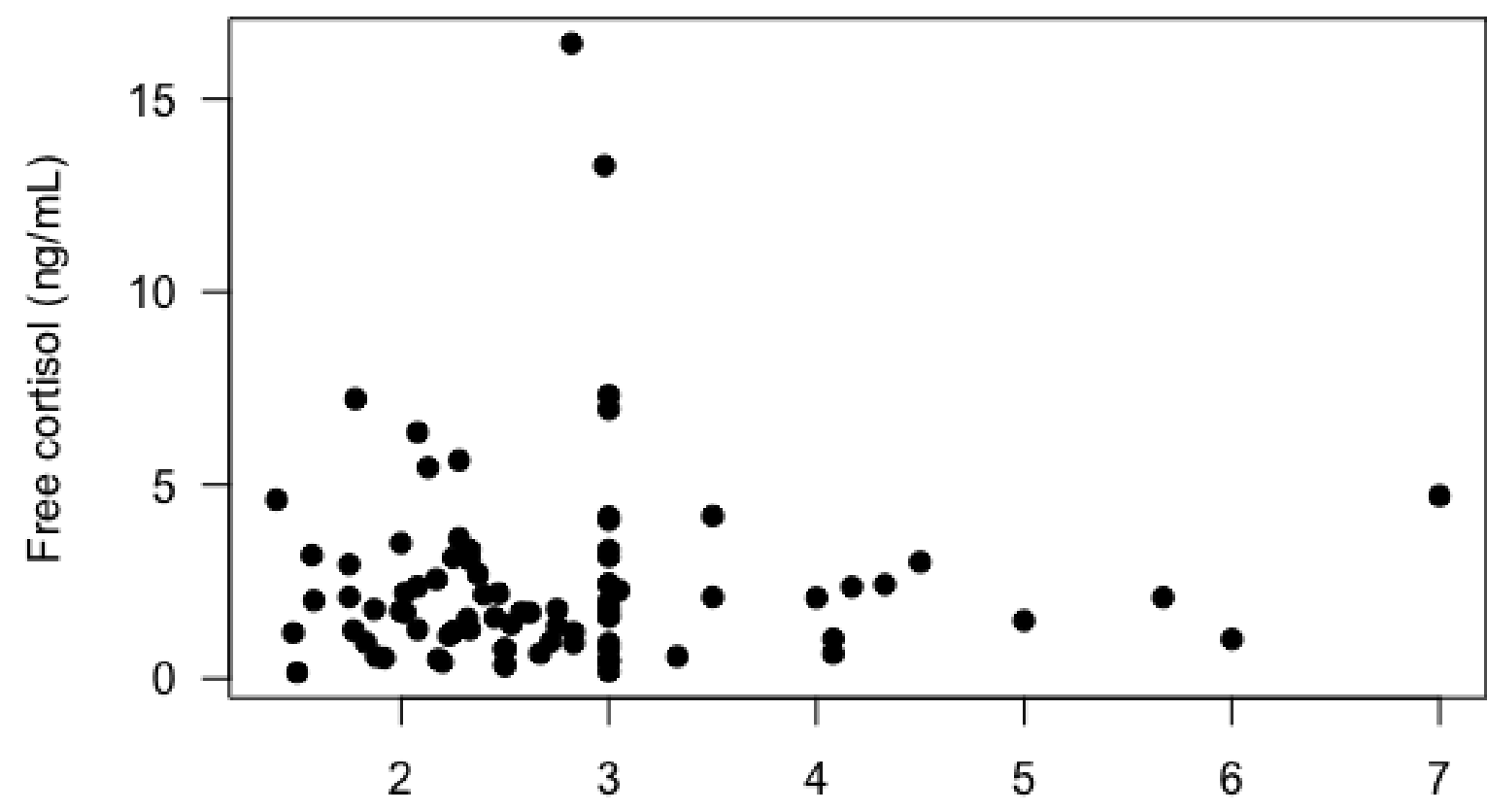

Sampling time (min)
Appendix 2 : Relationships between plasma total cortisol levels ( $\mathrm{ng} / \mathrm{mL}$ ) (top) and plasma free cortisol levels $(\mathrm{ng} / \mathrm{mL}$ ) (bottom) and sampling time $(\mathrm{min})$ in female Columbian ground squirrels 